\title{
Does choice of drought index influence estimates of drought-induced rice losses in India?
}

\begin{tabular}{|c|c|}
\hline Journal: & Environment and Development Economics \\
\hline Manuscript ID & EDE-18-288.R3 \\
\hline Manuscript Type: & Research Paper \\
\hline $\begin{array}{r}\text { Date Submitted by the } \\
\text { Author: }\end{array}$ & $\mathrm{n} / \mathrm{a}$ \\
\hline Complete List of Authors: & $\begin{array}{l}\text { Fontes, Francisco; FAO } \\
\text { Palmer, Charles; London School of Economics, Geography and } \\
\text { Environment; } \\
\text { Gorst, Ashley; Vivid Economics }\end{array}$ \\
\hline Keywords: & Agriculture, Rice, Climate, Drought, India, Rainfall, Temperature \\
\hline Abstract: & $\begin{array}{l}\text { Drought events have critical impacts on agricultural production yet there } \\
\text { is little consensus on how these should be measured and defined, with } \\
\text { implications for drought research and policy. We develop a flexible } \\
\text { rainfall-temperature drought index that captures all dry events and } \\
\text { classify these as Type } 1 \text { (above-average cooling degree-days, CDD) and } \\
\text { Type } 2 \text { droughts (below-average CDD). Applied to a panel dataset of } \\
\text { Indian districts over } 1966-2009 \text {, Type } 2 \text { droughts are found to have } \\
\text { negative marginal impacts comparable to those of Type } 1 \text { droughts. } \\
\text { Irrigation more effectively reduces Type } 2 \text { drought-induced yield losses } \\
\text { than Type } 1 \text { yield losses. Over time, Type } 1 \text { drought losses have declined } \\
\text { while Type } 2 \text { losses have risen. Estimates of average yield losses due to } \\
\text { Type } 1 \text { droughts are reduced by up to } 27 \% \text { when Type } 2 \text { droughts are } \\
\text { omitted. The associated ex-post economic costs in terms of rice } \\
\text { production are underestimated by up to } 124 \%\end{array}$ \\
\hline
\end{tabular}

\section{SCHOLARONE




\title{
DOES CHOICE OF DROUGHT INDEX INFLUENCE ESTIMATES OF DROUGHT- INDUCED RICE LOSSES IN INDIA?
}

\author{
Francisco Fontes $^{1,4}$, Ashley Gorst ${ }^{2,4}$, Charles Palmer ${ }^{3,4}$
}

\begin{abstract}
Drought events have critical impacts on agricultural production yet there is little consensus on how these should be measured and defined, with implications for drought research and policy. We develop a flexible rainfall-temperature drought index that captures all dry events and classify these as Type 1 (above-average cooling degree-days, CDD) and Type 2 droughts (below-average CDD). Applied to a panel dataset of Indian districts over 1966-2009, Type 2 droughts are found to have negative marginal impacts comparable to those of Type 1 droughts. Irrigation more effectively reduces Type 2 drought-induced yield losses than Type 1 yield losses. Over time, Type 1 drought losses have declined while Type 2 losses have risen. Estimates of average yield losses due to Type 1 droughts are reduced by up to $27 \%$ when Type 2 droughts are omitted. The associated ex-post economic costs in terms of rice production are underestimated by up to $124 \%$.
\end{abstract}

Keywords: Agriculture, Rice, Climate, Drought, India, Rainfall, Temperature

JEL classification: Q10, Q19, Q54, Q56

Acknowledgements: For helpful comments and suggestions, we thank the Editor and two anonymous referees, Bhavani Shankar, Ganga Shreedhar, Alban Thomas, and various colleagues in the Grantham Research Institute on Climate Change and the Environment (GRI) and participants at the Conference of Shocks and Development (Dresden). Francisco Fontes and Ashley Gorst acknowledge support from the Centre for Climate Change Economics and Policy, which is funded by the UK Economic and Social Research Council.

\footnotetext{
${ }^{1}$ Present affiliation \& address: Monitoring and Analyzing Food and Agricultural Policies (MAFAP) program, Agricultural Development Economics Division (ESA), Food and Agriculture Organization of the United Nations (FAO), Viale delle terme di Caracalla, 00153 Roma, Italy. Email: francisco.fontes@fao.org

2 Present affiliation \& address: Vivid Economics Ltd., 26-28 Ely Place, London EC1N 6TD, United Kingdom. Email: ashley.gorst@vivideconomics.com

${ }^{3}$ Department of Geography and Environment \& Grantham Research Institute on Climate Change and the Environment, London School of Economics and Political Science.
}

${ }^{4}$ Corresponding author. Phone: +44 207107 5093; email: c.palmer1@1se.ac.uk 


\section{Introduction}

Extended periods of low rainfall that reduce the availability of moisture relative to normal climate conditions constitute drought events (Mishra and Singh, 2010), with the severity of these events being aggravated by climatic factors such as temperature (Wilhite, 2000a). Since 1900, two billion people have been affected by drought and annual economic costs are estimated at US\$ 6-8 billion (FAO, 2013). A number of low- and middle-income countries, including those located in Sub-Saharan Africa and the Indian sub-continent, are particularly vulnerable to the impacts of drought. In India, the setting for our paper, severe drought lowered annual GDP by around two to five percent between 1951 and 2003 (Gadgil and Gadgil, 2006); among drought-affected households, drought led to a 12 to $33 \%$ increase in the poverty headcount ratio and a 25 to $60 \%$ decline in household income (Pandey et al., 2007). The onset of drought in India has also been empirically linked to conflict, rural wages and human capital accumulation (Jayachandran, 2006; Sarsons, 2015; Shah and Steinberg, 2017).

Against a backdrop of rising temperatures and drier conditions, droughts are projected to become more common with critical implications for agricultural production (IPCC, 2012). How meteorological drought is defined plays a central role in policymakers' responses, not only in the agricultural sector but also in the water sector and in early-warning systems. Yet, there is presently little consensus on how droughts might be measured and hence, defined. Indeed, there is no universal definition of the conditions constituting a drought (Wilhite, 2000b). A range of indices attempt to quantify the severity of a drought, ranging from simple rainfall measures to complex indices that account for rainfall, temperature and estimates of potential evapotranspiration $^{1}$ (Mishra and Singh, 2010). Different criteria of what constitutes a 'drought' therefore imply that a drought in one index may not constitute a drought in another.

\footnotetext{
${ }^{1}$ The combined process of water evaporated from land surfaces and plants.
} 
The implication is that, depending on the index used, there are classes of dry events which may be overlooked both in empirical analyses and by policymakers.

In this article, we develop a simple rainfall-temperature index that allows for a flexible characterisation of drought events. It captures every dry event, in which cumulative rainfall over the growing season is below average relative to the average long-term cumulative rainfall for the growing season, while accounting for temperature. The novelty of our index is to include both the type of dry events typically captured by indices that account for temperature, i.e. characterised by above-average values of cooling degree days (CDD), ${ }^{2}$ which we term 'Type 1' droughts, as well as ones characterised by below-average values of CDD. To our knowledge, the latter, which we term 'Type 2' droughts, have not been explicitly studied before.

Type 2 droughts are likely to have impacts that differ from those driven by Type 1 droughts. First, rainfall deficiency drives water stress thus negatively impacting on crop yields but the combined effects of heat and rainfall are likely to be greater than their individual impacts (Lamaoui et al., 2018). This implies that Type 1 droughts have higher potential impacts than Type 2 droughts. Second, for a Type 2 drought, a lower value of CDD over the growing season does not imply an absence of hot days. Heat stress, even for short periods of time, can cause permanent harm to plant growth (see, e.g., Luo, 2011). Third, some of the largest deviations in rainfall in India have occurred in years that were not considered particularly hot. In these years, impacts are likely to have been large and as such should not be overlooked.

Our index is applied to a panel dataset of Indian districts over the period 1966-2009 in order to estimate the marginal and total effects of each drought type on rice productivity. Rice is a principal food crop that is mainly grown in the kharif season (June to September). We also consider how, conditional on drought type, the marginal effects change over time, as well as

\footnotetext{
2 'Degree days' is a unit of temperature degree deviation from a benchmark during a 24-hour period. A 'cooling' degree day is a measure of heat, traditionally used to calculate the energy used to cool homes during a hot day.
} 
the extent to which they are mitigated by irrigation. Our base estimates are then used to calculate yield changes and associated ex-post economic impacts, which are likely to be underestimates given unobserved behavioural responses of farmers, e.g. if they engage in lower-risk lower-return activities because they anticipate the possibility of a drought (Elbers et al., 2007; Oviedo and Moroz, 2014). In a country where over two-thirds of total land area is vulnerable to drought (Ministry of Agriculture, 2009), and rain-fed agriculture covers approximately $60 \%$ of cropped area (Sharma, 2011), our analysis contributes to an important body of research on the impacts of droughts on Indian agriculture (e.g. Pandey et al., 2007; Sarkar, 2011).

After presenting background to our analysis in Section 2, we present Indian weather data underlying Type 1 and Type 2 droughts and propose an extension to a multiplicative index, developed by Yu and Babcock (2010), in Section 3. This extension allows for a more flexible characterization of drought events while retaining a key strength of their index, namely the inclusion of temperature and the capacity to capture the interaction between rainfall and temperature. Applied to our panel dataset of Indian districts, in Section 4, we find that Type 2 droughts consistently display large negative marginal and total effects, comparable to those of Type 1 droughts. The omission of Type 2 droughts leads to a large underestimation of total drought impact. Irrigation appears to be more effective at reducing Type 2 drought-induced yield losses than those attributed to Type 1 droughts. Over time, Type 1 drought losses, as a proportion of yield, have become smaller while Type 2 losses have risen. Yield and ex-post economic losses are shown in Section 5 to be underestimated by up to $27 \%$ and $124 \%$, respectively. We also test the forecasting accuracy of our index and we find that, while it outperforms the other indices considered, the improvements in terms of forecasting accuracy are marginal and statistically insignificant. Section 6 discusses the results and their implications for public policy. 


\section{Defining 'Drought'}

Simple drought indices often rely solely on rainfall measures and are typically preferred by policymakers, including the Indian Meteorological Department (IMD), over more complex indices. Until 2016, the IMD recorded a 'drought event' when seasonal rainfall was below 75\% of its long-term average (between 1950 and 2000), and a 'severe drought' when rainfall was below $50 \%$. Simple metrics of precipitation deficiency, which have the advantage of being easily interpretable, are also used to evaluate drought impacts on agricultural production, e.g. Pandey et al. (2007); Auffhammer et al. (2012).

Simple definitions of drought based on rainfall are, however, problematic for our understanding of drought impact. Variables in addition to rainfall, in particular temperature, help determine the physical severity of a drought. A growing literature suggests critical turning points at which higher temperatures cease to have positive impacts on agricultural yield, e.g. Schlenker and Roberts (2009); Guiteras (2009); Burgess et al. (2014); Lobell et al. (2012). High temperatures have particularly acute effects on crop growth during periods of low precipitation since the rate of evapotranspiration increases as temperatures rise (Prasad et al., 2008; Lobell and Gourdji, 2012). In general, this increases a plant's demand for water at a time when water availability is already low due to deficient precipitation. Drought is documented to increase in severity as mean temperatures have risen. Higher temperatures, rather than the increased intensity of low rainfall events, have been held responsible for these drying trends (Vicente-Serrano et al., 2014; Diffenbaugh et al., 2015). As such, neglecting the effect of temperature on the severity of a drought event could underestimate drought impact.

More complex indices tend to rely on data that are often not readily available in most economic datasets, e.g. for soil moisture levels. The lack of data needed to derive such measures, which can depend on factors such as wind, radiation and humidity, limits their applicability in empirical analysis of drought impacts. Bridging the gap between simple and 
complex indices, $\mathrm{Yu}$ and Babcock (2010) propose a drought index that neatly captures the interaction between temperature and rainfall thus giving it the potential to capture the combined effect of cumulative heat and water stress on yield. Applied to the study of drought tolerance of soybean and corn yields in the US, it takes a non-zero value for years of below-average rainfall and above-average values of CDD:

$$
D I_{i t}=\left[-\max \left(0, C D D_{i t}^{\text {stand }}\right)\right] *\left[\min \left(0, T R_{i t}^{\text {stand }}\right)\right]
$$

where: $D I_{i t}$ denotes the drought index for geographical unit $i$ in year $t ; T R_{i t}^{\text {stand }}$ is standardized total monthly rainfall over the growing season; and, $C D D_{i t}^{\text {stand }}$ is standardized, cumulative cooling degree days above $18^{\circ} \mathrm{C}$.

The index described in (1) gives a value of zero whenever either $C D D_{i t}^{\text {stand }}$ is below or $T R_{i t}^{\text {stand }}$ is above their respective long-term averages. Thus, a drought 'event' or 'year' is defined when $C D D_{i t}^{\text {stand }}$ is higher and $T R_{i t}^{\text {stand }}$ is lower than their respective long-term averages. A strength of this index lies in its capacity to capture the potential of high temperatures to exacerbate the effects of low rainfall on crop production. Birthal et al. (2015) adopt the index to study the tolerance of rice yields to drought in India.

While Yu and Babcock's (2010) approach has the advantage of being a relatively simple way to account for both temperature and precipitation, the index restricts the definition of drought to events characterised by below-average $T R_{i t}^{\text {stand }}$ accompanied by above-average values of $C D D_{i t}^{\text {stand }}$, our Type 1 drought. It does not consider events characterised by belowaverage values of $C D D_{i t}^{\text {stand }}$ as well as below-average $T R_{i t}^{\text {stand }}$, our Type 2 drought. Despite being common in many settings, the impacts of such events on agricultural production remain unknown, due to either being omitted altogether (as in Birthal et al. 2015) or joined with Type 1 droughts in arbitrarily-defined rainfall indices. 
Type 2 droughts should not be omitted a priori because, as explained in the introduction, focusing only on years with an above-average value of $C D D_{i t}^{\text {stand }}$ (Type 1 drought) ignores the possibility that in years with a below-average value of $C D D_{i t}^{\text {stand }}$ there may still be a number of very hot days sufficient to negatively impact on agricultural productivity. ${ }^{3}$ Thus, a class of potentially destructive dry events would not be defined as 'drought' per equation (1), which may underestimate the aggregate impact of all dry events. The classification of these events as non-droughts could lead to biased estimates of drought impact. Thus, if Type 2 droughts do have a significant negative impact on productivity, then the application of Yu and Babcock's index potentially underestimates drought impacts due to the inclusion of Type 2 drought events in the 'no drought' control group. Finally, since we expect crops to respond differently to increasing deviations from mean rainfall, depending on whether the value of $C D D_{\text {it }}^{\text {stand }}$ is below- or above-average, Type 2 droughts ought not only to be included but also modelled separately from Type 1 droughts.

Our definitions of drought - Type 1 and Type 2 - are important for understanding and predicting crop yields. We argue that they are an improvement on measures and indices used in earlier research. Table 1 lists previous studies that have adopted both simple and more complex non-linear functions of temperature and rainfall as predictors for crop yields. In general, these measures focus on either heat or rainfall thus neglecting the combined impact on yield from cumulative heat and water stress. One possible reason is that the temperature bins approach is often used and requires a very large number of coefficients to estimate the combined effect of heat and rainfall. Previous work on drought impacts also typically adopts a single binary definition to estimate the impact of drought on yields. However, the use of a binary definition makes it difficult to assess the relationship between drought and yield.

\footnotetext{
${ }^{3}$ In Yu and Babcock (2010), a below-average value of $C D D_{\text {it }}^{\text {stand }}$ means that the cumulative sum of degree-days above $18^{\circ} \mathrm{C}$ over a given period is lower than its long-term average. While this suggests lower cumulative heat during the season, it does not imply an absence of hot days and/or temperature spikes during the growing season.
} 


\section{Table 1: List of previous studies}

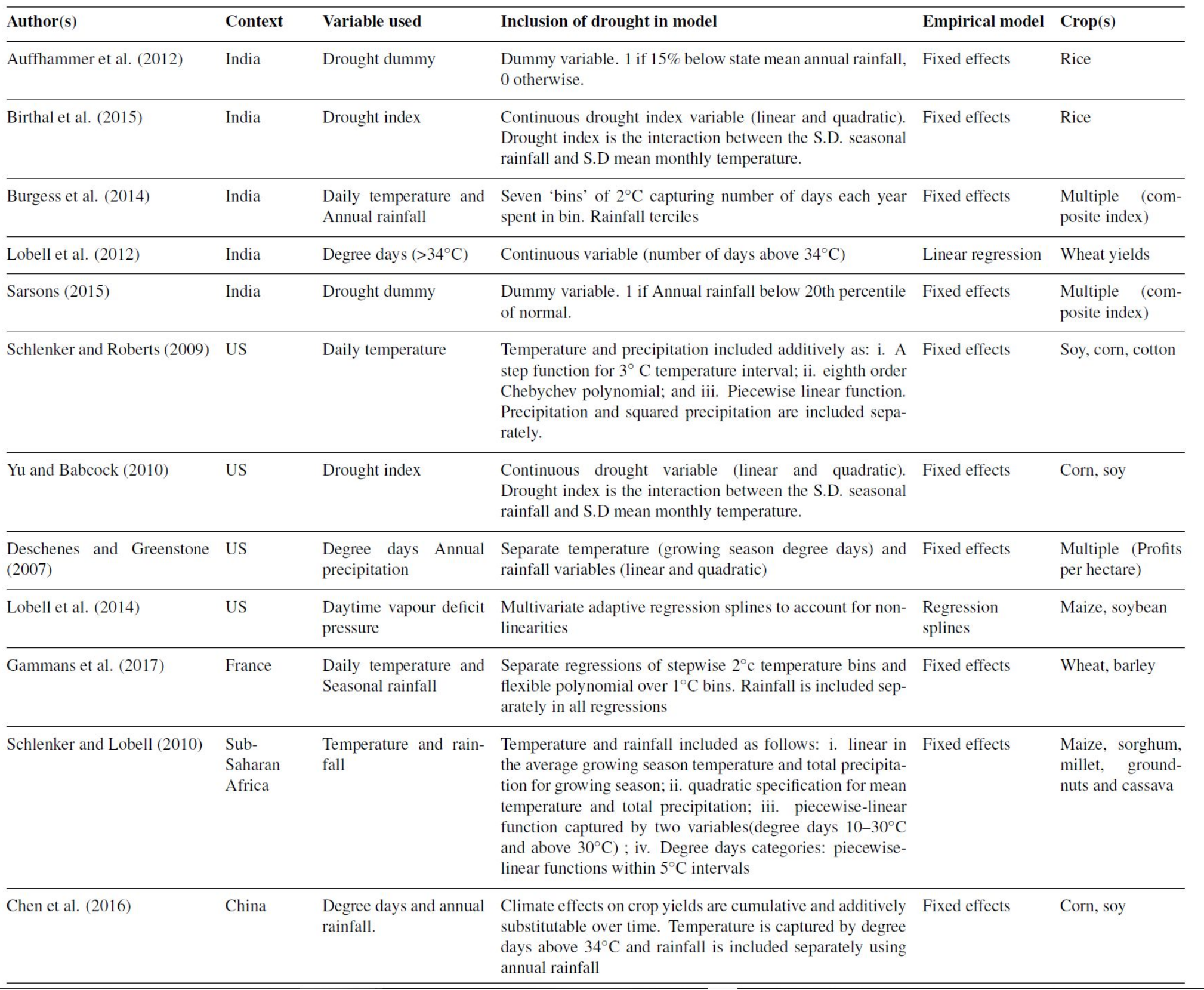




\section{A New Index to Define Drought in India}

Weather data on daily rainfall and daily average temperature at the district level are sourced from the IMD to Figures 1 and $2 .{ }^{4}$ We define our growing season as June-September ${ }^{5}$ and both long-term average rainfall and CDD are defined vis-à-vis their 1956-2009 averages. $^{6}$

Panel (a) of Figure 1 shows the proportion of districts, by year, limited to events characterized by both below-average rainfall and above-average values of CDD (Type 1). The vertical blue lines indicate All-India Drought Years. ${ }^{7}$ Panel (b) of Figure 1 shows the proportion of districts in years characterised by below-average rainfall and below-average values of CDD (Type 2).

Figure 1: Proportion of affected districts, by drought type

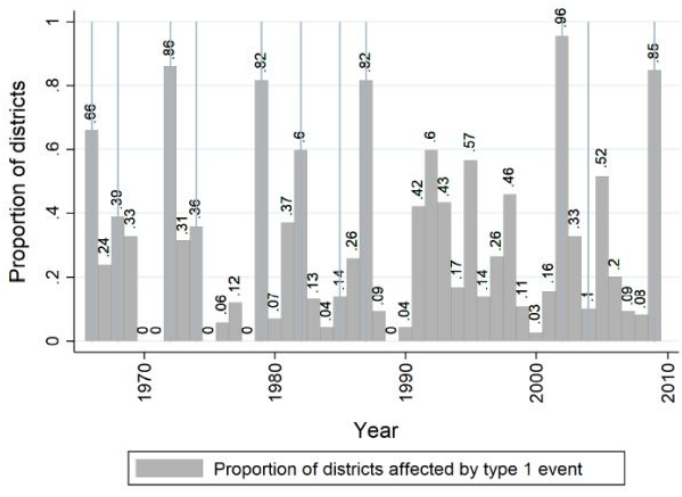

(a) Proportion affected (Type 1)

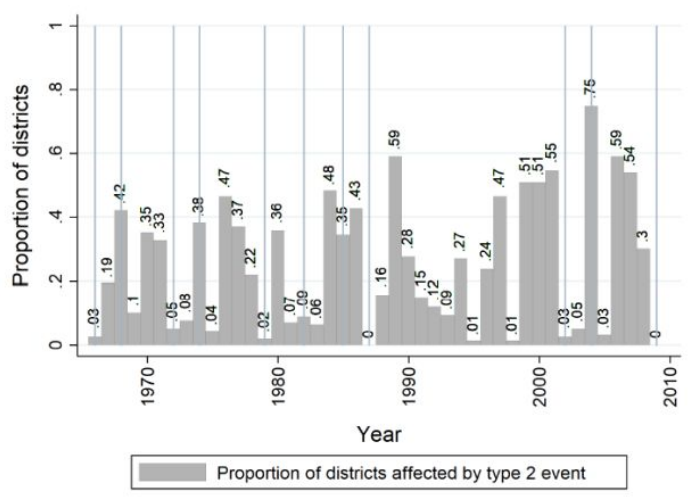

(b) Proportion affected (Type 2)

Notes: The numbers above the bars represent the proportion of districts (rounded to two decimal places) that were affected by a given drought type in a given year. Source: Authors own calculations

\footnotetext{
${ }^{4}$ The weather data were obtained under licence from IMD for a fee. The rainfall data are available in gridded format at a resolution of $0.25^{\circ} \times 0.25^{\circ}$ (Pai et al., 2014). Gridded temperature data are at a resolution of $1^{\circ} \times 1^{\circ}$ (Srivastava et al., 2009). District-level weather data are then obtained by taking a weighted average of gridded weather observations from grid cells that fall within a district's boundary based on the proportion of the grid cell that falls in each district.

${ }^{5}$ The majority of India's rice production is cultivated in the kharif season, between June and September, and the majority of total yearly rainfall (approximately 80\%) also falls between these months (Jain and Kumar, 2012).

${ }^{6}$ The reference temperature for the CDD is the average June-September daily temperature for the district between 1956 and 2009. The CDD variable is calculated as $C D D_{i t}=\sum_{m=1}^{M} \sum_{d=1}^{D}\left(D T_{i m d}-D T A_{i}\right)$, where we subtract the average daily temperature over the growing season observed from 1956-2009 $\left(D T A_{i}\right)$ from the observed daily temperature $\left(D T_{i m d}\right)$. We then sum all the positive deviations over the growing period and give a value of 0 to negative deviations. See Appendix A.

${ }^{7}$ According to the IMD, 13 'All-India Drought Years' have been recorded since 1966 (Birthal et al., 2015). Such 'Drought Years' were recorded when the total area affected by a moderate or severe drought covered $20-40 \%$ of the total land area of the country and rainfall during the monsoon season fell $10 \%$ below average seasonal rainfall recorded between 1950 and 2000 . When more than $40 \%$ of the total land area was affected by drought, this was termed an 'All India Severe Drought Year'.
} 
Figure 2 shows why the omission of Type 2 droughts is likely to be problematic. For each year, we estimate the number of districts affected by Type 1 droughts net of the number of those affected by Type 2 droughts, with a positive number (in darker grey) denoting a year in which the former exceeds the latter. A negative number (in lighter grey) indicates a year in which the latter exceeds the former. Overall, Type 1 droughts are slightly more prevalent (55\%) than Type 2 droughts (45\%). In the 1990s, most of the drought-affected districts were affected by Type 1 droughts. Since 1999, Type 2 droughts have increased, with the number of districts affected by Type 2 droughts outnumbering the number of districts affected by Type 1 droughts in seven out of 11 years.

Figure 2: Type 1 droughts in excess of Type 2 droughts (June-September only)

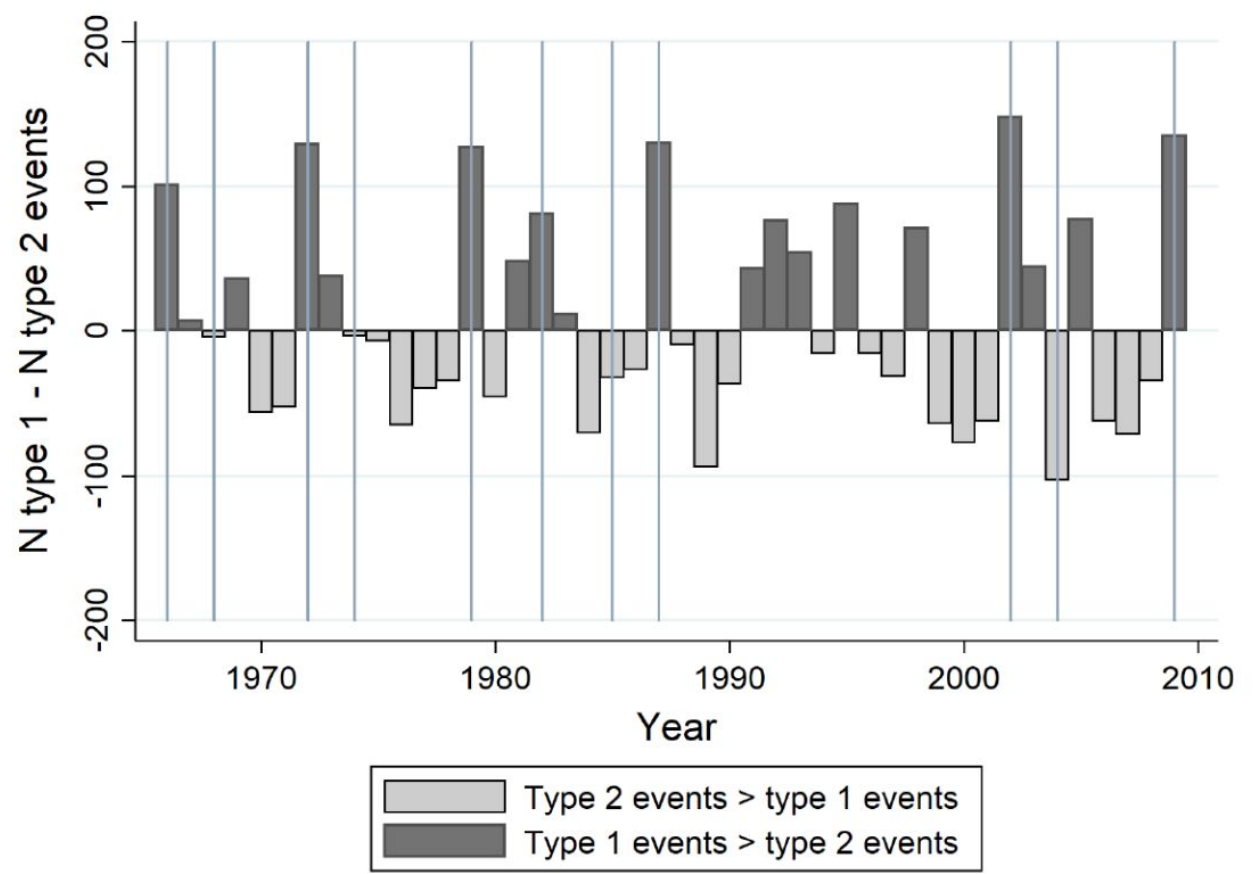

Notes: The scatter points highlight the total number of droughts (by type) in a given year. In the case of Type 1 droughts (red scatter points) these can be interpreted directly (i.e. 200 means that 200 districts were affects by a Type 1 drought). However, in the case of the Type 2 droughts, these should be interpreted as the negative of the number (i.e. if the observed value is -100 , this means there were 100 districts affected by Type 2 droughts). Bar graphs show the number of affected districts affected by Type 1 droughts in excess of the number affected by Type 2 droughts. As a result a result a value of 50 would mean that there were 50 more districts affected by a Type 1 drought than affected by a Type 2 drought in a given year. The converse applies to a negative number, which highlights a higher number of districts affected by type 2 droughts in a given year.

The solid vertical lines represent the years considered by the Indian Government as All-India drought years.

Source: Authors own calculations 
Formally shown in Appendix A, the first step of our index involves the calculation of the deviation of CDD over the growing season (June-September) from average long-run (19562009) CDD over the growing season, a variable we define as DCDD. Positive values of DCDD indicate above-average CDD while negative values indicate below-average CDD. A similar procedure is followed for rainfall in that we create a variable, DTR, which is defined as the deviation of district-specific, cumulative rainfall from long-term, mean cumulative rainfall between 1956 and 2009. Negative values of DTR represent below-average cumulative rainfall while positive values indicate above-average rainfall.

Next, we normalize DCDD and the negative of DTR, which we define as $\mathrm{NCDD}_{\text {it }}$ and $\mathrm{NTR}_{\mathrm{it}}$, respectively. Normalizing the negative of rainfall, rather than rainfall directly, allows us to generate a variable bounded between 0 and 1, with higher values signalling more severe rainfall deficiency. Thus, $\mathrm{NCDD}_{\mathrm{it}}$ is increasing in temperature and $\mathrm{NTR}_{\mathrm{it}}$ is increasing in rainfall deficiency. Using the normalized negative of rainfall enables us to construct an index without running into the problem of negative values that emerges from the interaction of the standardized variables. Finally, a multiplicative relationship is generated between the two normalized variables, resulting in two drought indices. Type 1 droughts are denoted $D I 1_{\mathrm{it}}$ and Type 2 are denoted $D I 2_{\text {it }}$ :

$$
\text { Drought }=\left\{\begin{array}{l}
D I 1_{\mathrm{it}}=\mathrm{NTR}_{\mathrm{it}} * \mathrm{NCDD}_{\mathrm{it}} \text { if } \mathrm{DTR}_{\mathrm{it}}<0 \text { and } \mathrm{DCDD}_{\mathrm{it}}>0 ; 0 \text { otherwise } \\
D I 2_{\mathrm{it}}=\mathrm{NTR}_{\mathrm{it}} * \mathrm{NCDD}_{\mathrm{it}} \text { if } \mathrm{DTR}_{\mathrm{it}}<0 \text { and } \mathrm{DCDD}_{\mathrm{it}}<0 ; 0 \text { otherwise }
\end{array}\right.
$$

As such, $D I 1_{\text {it }}$ can be interpreted as a normalized version of Yu and Babcock's (2010) index. It takes a strictly positive value for all events characterized by below-average rainfall and above-average $C D D_{i t}^{\text {stand }}$. The second index, $D I 2_{\text {it }}$, only takes non-zero values for events with below-average rainfall and below-average $C D D_{i t}^{\text {stand }}$, the category $\mathrm{Yu}$ and Babcock omit. Constructing these two indices separately allows us to test their respective statistical significance in the yield regressions. 
Our indices are increasing in temperature but decreasing in rainfall and reflect that both higher temperatures and lower rainfall are expected to contribute to drought severity. A maximum value of one is obtained for the most severe droughts, and is only possible for the restricted set of drought events considered by Yu and Babcock. The similarity of their index to our own is illustrated in Appendix table 1, which shows the correlation coefficients and the spearman correlation coefficient. As expected, our index $D I 1$ is highly correlated with YuBabcock, displaying a correlation coefficient of 0.787 and a spearman correlation coefficient in excess of 0.99 . Our second index $D I 2$, on the other hand, has a negative correlation coefficient with a correlation coefficient of -0.189 and a spearman coefficient of -0.363 . Since Yu-Babcock is invariant with a value of zero for these events, this result is also as anticipated. In addition, these two indices differ in terms of their maximum values. While the maximum value for Type 1 droughts is one (which occurs when the hottest year is also the year with the lowest rainfall), the maximum value of events in which both rainfall and CDD are belowaverage is 0.54 (see Table 2). These two maximum values capture the fact that a combination of above-average CDD with below-average rainfall is likely to lead to more severe drought than below-average CDD combined with below-average rainfall.

Table 2: Summary Statistics of observations in the sample

\begin{tabular}{llllll}
\hline Variables & N & Mean & S.D & Min & Max \\
\hline Rice area (1,000 ha) & 6996 & 122.49 & 141.65 & 0.09 & 956.63 \\
Rice irrigated area (1,000 ha) & 6996 & 74.97 & 103.22 & 0.00 & 663.70 \\
Rice yield (t/ha) & 6996 & 1.63 & 0.95 & 0.01 & 4.78 \\
Proportion of cereal area under rice production & 6996 & 0.36 & 0.29 & 0.00 & 1.00 \\
Rural population density (by gross cereal area) & 6995 & 3.40 & 1.67 & 0.62 & 13.68 \\
Fertiliser (t/ha) & 6996 & 71.45 & 67.50 & 0.00 & 614.49 \\
Cumulative rainfall (mm) (June-September) & 6996 & 755.38 & 417.48 & 28.89 & 4557.98 \\
Cooling degree days (CDD, June-September) & 6996 & 100.36 & 48.07 & 2.70 & 274.88 \\
Babcock-Yu index, June-September & 6996 & 0.25 & 0.66 & 0.00 & 8.53 \\
DI1 (Drought index - type 1 events) & 6996 & 0.15 & 0.25 & 0.00 & 1.00 \\
DI2 (Drought index - type 2 events) & 6996 & 0.05 & 0.10 & 0.00 & 0.54 \\
\hline
\end{tabular}

Notes: Rural population density is calculated by dividing total rural population by gross cropped area. Our cooling degree-days measure is calculated based on average daily district temperature in the months of June-September for the period 1956-2009. 
Figure 3 shows how our index values change over time for all districts. There are clear spikes in the values of the index for a number of All-India Drought Years. The years 2002 and 2009 are associated with the largest deviations in rainfall. Similarly, 1972, 1979, 1987 are also considered years with particularly high deviations and our index rises in these years. Throughout the 1990s, however, it is striking that, despite relatively modest deviations of rainfall from trend, our index still records high values. One possible explanation for this could be rising land-surface air temperatures over time (Pai et al., 2013).

Figure 3: Average drought index value

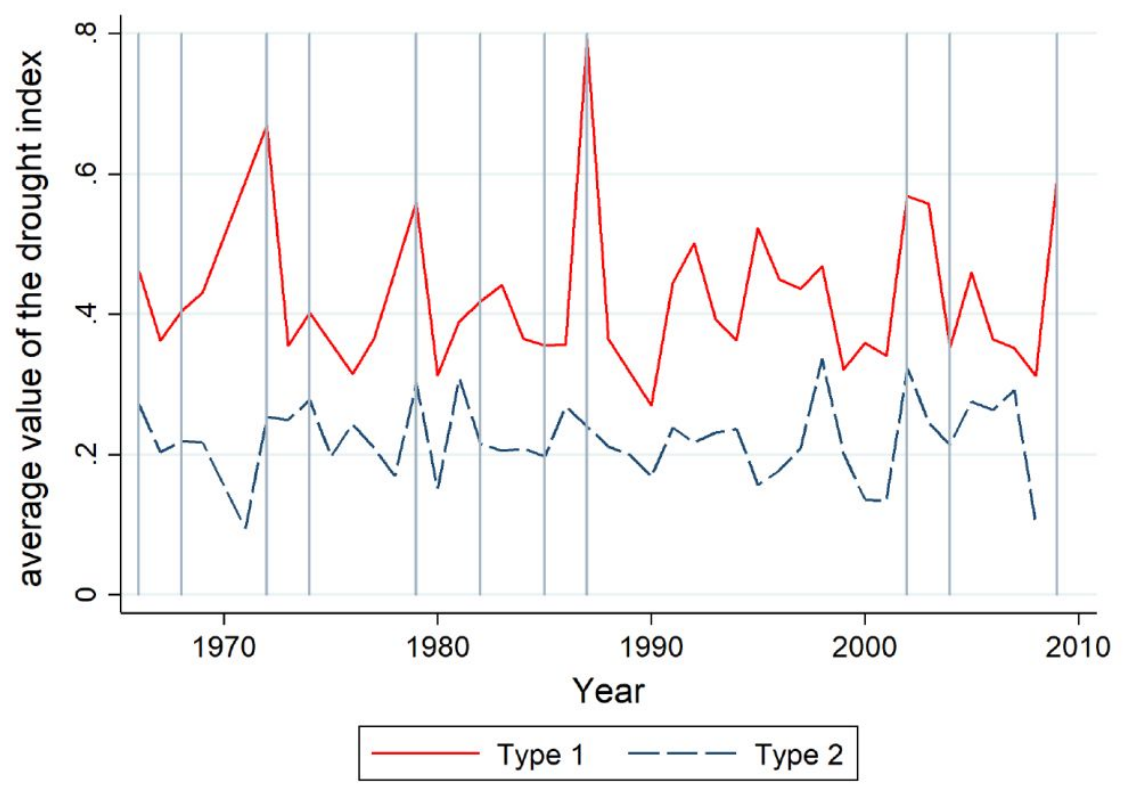

\section{Impact of Drought on Rice Productivity}

To investigate drought impacts on aggregate rice productivity at the district level, we obtain agricultural data from the ICRISAT Meso-level Database. ${ }^{8}$ For the period 1966-2009, this dataset contains detailed agricultural and socioeconomic information (ICRISAT, 2012). Data are available for annual crop production and area under crop production for a range of crops, for most districts. Focusing on rice, we create a balanced panel, which implies that, of the 311

\footnotetext{
${ }^{8}$ Since 1966, a number of districts have split into smaller districts. To maintain spatial consistency over time district splits are dealt with by returning split districts to their 'parent' districts as of 1966.
} 
districts available in the dataset only 159 are used in our empirical analysis due to missing data for irrigated rice area (see map: Appendix Figure 1). Rice yield is estimated by dividing total rice production by total rice area. Table 2 summarises the variables used in our analysis.

To model the relationship between rice yield and our drought index, we estimate the following fixed-effects model: ${ }^{9}$

$\ln \left(y_{i t}\right)$

$$
\begin{aligned}
& =\alpha_{i}+\gamma_{t}+\delta_{i 1} * t+\delta_{i 2} * t^{2}+\beta_{1 q} D I_{i t q}+\beta_{2 q} D I_{i t q}^{2}+\beta_{3 q} D I_{i t q} * t+\beta_{4 q} D I_{i t q}^{2} * t \\
& +\beta_{5 q} D I_{i t q} * \text { propirri }_{i t}+\beta_{6 q} D I_{i t q}^{2} * \text { propirri }_{i t}+\epsilon_{i t}
\end{aligned}
$$

where for district $i$ in year $t: \operatorname{In}\left(y_{i t}\right)$ denotes the natural logarithm of rice yield; $\alpha_{i}$ and $\gamma_{t}$ represent the district and year fixed effects, respectively; $\delta_{i 1}$ and $\delta_{i 2}$ are the coefficients on the district-specific linear and quadratic trends, respectively. Quadratic terms are also included for the following variables, to account for potential nonlinearities in the relationship between drought type and yield. First, the coefficients associated with a type $q$ (i.e. Type $1-$ aboveaverage CDD, or Type 2 - below-average CDD) drought index, which captures the marginal impact of a type $q$ drought, are denoted $\beta_{1 q}$ and $\beta_{2 q}$. Coefficients $\beta_{3 q}$ and $\beta_{4 q}$ capture the interaction between drought type and time, $t$, while the coefficients $\beta_{5 q}$ and $\beta_{6 q}$ capture the interaction between drought type and the proportion of rice area under irrigation. Finally, $\epsilon_{i t}$ represents the error term. Consistent with Yu and Babcock (2010) and Birthal et al. (2015), we do not include additional controls in our main specifications. This is also the norm in the climate impacts literature.

\subsection{Regression Results}

We run a regression of the natural logarithm of yield on a set of district-specific quadratic trends and the drought indices. Specifically, we estimate the model in (3), in both log-levels

\footnotetext{
9 We prefer a fixed-effects model over a pooled ordinary least squares because it captures time-invariant heterogeneity. Also, a Hausman test rejected a random-effects model in favour of a fixed-effects model.
} 
and levels. First, we include only Type 1 drought events (columns 1 and 3 in Table 3). Second, we estimate separate coefficients for Type 1 and Type 2 drought events (columns 2 and 4 in Table 3).

Table 3 highlights two results. ${ }^{10}$ First, at mean drought intensity (the average for all events with non-zero index values), both drought types have significant and negative effects when considered separately. Thus, Type 2 events have large and statistically significant, negative impacts on rice yield. Second, we find that at means of all variables, Type 2 droughts have a higher marginal effect on yield. However, as will be shown in the next section, the overall effects on yield and associated economic costs are higher for Type 1 droughts. This is because the index value of Type 2 droughts is typically around half of the index value of Type 1 droughts. ${ }^{11}$ Although both excess heat and reduced moisture have negative impacts on production, reduced rainfall carries greater weight in the Type 2 index than in the Type 1 index, explaining the greater marginal effect. Values of CDD are, by definition, higher in the latter than in the former. As a result, yields are likely to respond (more) negatively to changes in the Type 2 index than in the Type 1 index.

The differences in impacts between Type 1 and Type 2 are tested into two ways. First, the confidence intervals of the marginal effects at means for the two drought types are shown in Table 3 (see rows '95\% CI'). The DI2 marginal effect (evaluated at means of all variables) is outside the $95 \% \mathrm{CI}$ of the DI1 marginal effect (again at means of all variables) for the levels specification and it is just marginally inside the $90 \%$ CI for the log-levels specification. Second,

\footnotetext{
10 The R-squared (within, between and overall) are estimated for three different regressions and are shown in Appendix Table 2: district and year fixed effects; district and year fixed effects plus a district-specific quadratic trend; and, all the variables included in Table 3. These results suggest that trends have a high explanatory power (overall R-squared increases from 0.168 to 0.645 (levels) and 0.164 to 0.22 (log-levels) following their inclusion). The results also suggest that adding the remaining variables (irrigation, drought indices and their interactions) leads to an improvement in the explanatory power of the model (overall R-squared increases from 0.645 to 0.775 (levels) and from 0.22 to 0.446 (log-levels)).

${ }^{11}$ A value of 0.5 in our Type 2 index represents approximately the same rainfall deficiency as a value of one in our Type 1 index, which helps explain larger marginal impacts.
} 
we tested whether all the $D I 1$ coefficients (and interactions) are jointly different from all the DI2 coefficients (and their interactions) (see Appendix table 3). For the log-levels specification, the F-test was rejected at the $10 \%$ level. For the levels specification, the hypothesis that the coefficients are equal could not be rejected. This may be due to the large number of interactions included in the model. 
Table 3: Full sample results

\begin{tabular}{|c|c|c|c|c|}
\hline \multirow[b]{2}{*}{ Variables } & \multicolumn{2}{|c|}{ Levels } & \multicolumn{2}{|c|}{ Log-levels } \\
\hline & 1 & 2 & 3 & 4 \\
\hline & Type 1 only & Type 1 and 2 & Type 1 only & Type 1 and 2 \\
\hline Drought index (type 1) & $\begin{array}{l}-0.352 * * * \\
(0.114)\end{array}$ & $\begin{array}{l}-0.450 * * * \\
(0.118)\end{array}$ & $\begin{array}{l}-0.656^{* * * *} \\
(0.189)\end{array}$ & $\begin{array}{l}-0.828 * * * \\
(0.200)\end{array}$ \\
\hline Drought index (type 1$)^{2}$ & $\begin{array}{l}0.119 \\
(0.172)\end{array}$ & $\begin{array}{l}0.201 \\
(0.175)\end{array}$ & $\begin{array}{l}0.09 \\
(0.296)\end{array}$ & $\begin{array}{l}0.234 \\
(0.299)\end{array}$ \\
\hline Drought index (type 1)*time & $\begin{array}{l}0.009 * * \\
(0.004)\end{array}$ & $\begin{array}{l}0.009 * * \\
(0.004)\end{array}$ & $\begin{array}{l}0.007 * \\
(0.004)\end{array}$ & $\begin{array}{l}0.006 \\
(0.004)\end{array}$ \\
\hline Drought index (type 1$)^{2} *$ time & $\begin{array}{l}-0.013 * * \\
(0.007)\end{array}$ & $\begin{array}{l}-0.012^{*} \\
(0.006)\end{array}$ & $\begin{array}{l}-0.003 \\
(0.006)\end{array}$ & $\begin{array}{l}-0.002 \\
(0.006)\end{array}$ \\
\hline Drought index (type 1)*Irrigation & $\begin{array}{l}0.079 \\
(0.125)\end{array}$ & $\begin{array}{l}0.088 \\
(0.132)\end{array}$ & $\begin{array}{l}0.552 * * * \\
(0.190)\end{array}$ & $\begin{array}{l}0.698 \text { *** } \\
(0.202)\end{array}$ \\
\hline Drought index (type 1$)^{2} *$ irrigation & $\begin{array}{l}-0.028 \\
(0.169)\end{array}$ & $\begin{array}{l}-0.044 \\
(0.173)\end{array}$ & $\begin{array}{l}-0.203 \\
(0.256)\end{array}$ & $\begin{array}{l}-0.322 \\
(0.261)\end{array}$ \\
\hline Drought index (type 2) & & $\begin{array}{l}-0.750 * * \\
(0.342)\end{array}$ & & $\begin{array}{l}-1.185^{* * * *} \\
(0.336)\end{array}$ \\
\hline Drought index (type 2$)^{2}$ & & $\begin{array}{l}1.314 \\
(1.166)\end{array}$ & & $\begin{array}{l}1.912 \\
(1.204)\end{array}$ \\
\hline Drought index (type 2)*time & & $\begin{array}{l}0.007 \\
(0.011)\end{array}$ & & $\begin{array}{l}0.016 \\
(0.010)\end{array}$ \\
\hline Drought index (type 2$)^{2} *$ time & & $\begin{array}{l}-0.033 \\
(0.034)\end{array}$ & & $\begin{array}{l}-0.073 * * \\
(0.035)\end{array}$ \\
\hline Drought index (type 2 )*Irrigation & & $\begin{array}{l}0.43 \\
(0.327)\end{array}$ & & $\begin{array}{l}0.602^{*} \\
(0.316)\end{array}$ \\
\hline Drought index (type 2$)^{2} *$ irrigation & & $\begin{array}{l}-1.461 \\
(1.117)\end{array}$ & & $\begin{array}{l}0.047 \\
(1.155)\end{array}$ \\
\hline Irrigation (prop) & $\begin{array}{l}0.735 \text { *** } \\
(0.162)\end{array}$ & $\begin{array}{l}0.757 * * * \\
(0.161)\end{array}$ & $\begin{array}{l}0.428 * * * \\
(0.125)\end{array}$ & $\begin{array}{l}0.451 * * * \\
(0.124)\end{array}$ \\
\hline Irrigation (prop) ${ }^{2}$ & $\begin{array}{l}-0.256^{* *} \\
(0.100)\end{array}$ & $\begin{array}{l}-0.266^{* * * *} \\
(0.100)\end{array}$ & $\begin{array}{l}-0.158^{* *} \\
(0.076)\end{array}$ & $\begin{array}{l}-0.194 * * \\
(0.077)\end{array}$ \\
\hline Constant & $\begin{array}{l}0.786 * * * \\
(0.064)\end{array}$ & $\begin{array}{l}0.810 * * * \\
(0.063)\end{array}$ & $\begin{array}{l}-0.293^{* * * *} \\
(0.047)\end{array}$ & $\begin{array}{l}-0.254^{* * * *} \\
(0.047)\end{array}$ \\
\hline $\begin{array}{l}\text { Marginal elasticity DI1 (at DI } 1=0.493 \text { ) } \\
95 \% \text { CI } \\
\text { Marginal elasticity DI2 (at DI2 }=0.207 \text { ) } \\
95 \% \text { CI }\end{array}$ & $\begin{array}{l}-0.293 * * * \\
(-0.37,-0.22)\end{array}$ & $\begin{array}{l}-0.305 * * * \\
(-0.38,-0.23) \\
-0.462 * * * \\
(-0.65,-0.28)\end{array}$ & $\begin{array}{l}-0.283 * * * \\
(-0.38,-0.18)\end{array}$ & $\begin{array}{l}-0.294 * * * \\
(-0.39,-0.20) \\
-0.375 * * * \\
(-0.54,-0.21)\end{array}$ \\
\hline Time trends & $\checkmark$ & $\checkmark$ & $\checkmark$ & $\checkmark$ \\
\hline District fixed effects & $\checkmark$ & $\checkmark$ & $\checkmark$ & $\checkmark$ \\
\hline Year fixed effects & $\checkmark$ & $\checkmark$ & $\checkmark$ & $\checkmark$ \\
\hline $\mathrm{N}$ & 6996 & 6996 & 6996 & 6996 \\
\hline Number of districts & 159 & 159 & 159 & 159 \\
\hline R-squared a & 0.725 & 0.729 & 0.600 & 0.611 \\
\hline R-squared w & 0.739 & 0.744 & 0.621 & 0.632 \\
\hline
\end{tabular}

Notes: Values in parentheses denote clustered standard errors at the district level. *, ** and *** denote statistical significance at the $10 \%, 5 \%$ and $1 \%$ level, respectively. Time trends denote quadratic districtspecific trends. 
The estimated change in marginal effects by irrigation and over time are presented, respectively, in Tables 4 and 5 for the levels specifications. The marginal effects for the loglevels specifications are shown in Appendix tables 4 and 5.

From Table 4, the levels specification results suggest that absolute drought impacts either remain fairly constant (Type 1) or increase (Type 2) as the proportion of rice area under irrigation rises. Yet, as a proportion of total yield results, from the log-levels specification, suggest that the marginal effect decreases substantially as the proportion of rice area under irrigation increases, as expected (Appendix table 4). This can be explained by the fact that yields in irrigated areas tend to be higher and, even if losses remain constant or increase moderately in absolute terms, yield increases from improved irrigation implies a fall in losses as a proportion of the total. Our results also suggest that, as a proportion of the total, increases in the proportion of rice area under irrigation reduce the marginal impact more when considering Type 2 droughts compared with Type 1 droughts. With increasing proportion of rice area under irrigation (above 95\% irrigated), impacts of Type 2 droughts (at mean intensity) are not significantly different from zero (at the 5\% level). The same does not apply for Type 1 droughts: even when the proportion of rice area under irrigation is very high we still find statistically significant effects on yields. This suggests that irrigation seems to be an effective strategy at substituting for water deficiency, but less effective at mitigating the combined effects of heat and water deficiency. 
Table 4: Levels specification: Marginal elasticities (irrigation) proportion of area irrigated

\begin{tabular}{llccc}
\hline & & \multicolumn{2}{c}{ Type 1 only } & \multicolumn{2}{c}{ Types 1 and 2 (sep.) } \\
\hline Variable & Value & Type 1 & Type 1 & Type 2 \\
\hline Irrigated area (\%) & 0 & $-0.32 * * *$ & $-0.33 * * *$ & $-0.36 * * *$ \\
Irrigated area (\%) & 20 & $-0.31 * * *$ & $-0.32 * * *$ & $-0.40 * * *$ \\
Irrigated area (\%) & 40 & $-0.30 * * *$ & $-0.31 * * *$ & $-0.43 * * *$ \\
Irrigated area (\%) & 60 & $-0.29 * * *$ & $-0.30 * * *$ & $-0.47 * * *$ \\
Irrigated area (\%) & 80 & $-0.28 * * *$ & $-0.30 * * *$ & $-0.50 * * *$ \\
Irrigated area (\%) & 100 & $-0.27 * * *$ & $-0.29 * * *$ & $-0.54 * * *$ \\
\hline
\end{tabular}

Notes: $*, * *$ and $* * *$ denote statistical significance at the $10 \%, 5 \%$ and $1 \%$ level, respectively. For both types of events marginal effects are computed at the mean value when affected (DI1 $=0.493$ and $\mathrm{DI} 2=0.207)$.

From Table 5, the results over time suggest that absolute yield losses attributed to drought have increased. As a proportion of total production, the log-levels specification in Appendix table 5 shows that losses follow a different pattern depending on the type of drought. ${ }^{12}$ Type 1 drought impacts as a proportion of the total have fallen over time whereas Type 2 impacts have increased. Two potential explanations for this result can be derived from our data and are summarized in Figure 4.

\footnotetext{
${ }^{12}$ An F-test, of differences in the $D I 1$ and $D I 2$ trends shows that, for the log-level estimation, equality of the trend coefficients was rejected at the $5 \%$ level, which is not the case for the levels specification (see Appendix Table 3). However, in the case of the levels specifications, the marginal effect of Type 2 droughts evaluated at the mean of the drought index (and all other covariates) at different points in time is often outside the $95 \%$ confidence interval of the marginal effect for the Type 1 drought evaluated at its mean and at the same point in time.
} 
Table 5: Levels specification: Marginal elasticities (time)

\begin{tabular}{lllll}
\hline & \multicolumn{2}{c}{ Type 1 only } & \multicolumn{2}{c}{ Types 1 and 2 (sep.) } \\
\hline Variable & Value & Type 1 & Type 1 & Type 2 \\
\hline Year & 1966 & $-0.21 * * *$ & $-0.23 * * *$ & $-0.31 *$ \\
Year & 1970 & $-0.22 * * *$ & $-0.24 * * *$ & $-0.34 * *$ \\
Year & 1974 & $-0.24 * * *$ & $-0.26 * * *$ & $-0.37 * * *$ \\
Year & 1978 & $-0.26 * * *$ & $-0.27 * * *$ & $-0.40 * * *$ \\
Year & 1982 & $-0.27 * * *$ & $-0.29 * * *$ & $-0.42 * * *$ \\
Year & 1986 & $-0.29 * * *$ & $-0.30 * * *$ & $-0.45 * * *$ \\
Year & 1990 & $-0.30 * * *$ & $-0.31 * * *$ & $-0.48 * * *$ \\
Year & 1994 & $-0.32 * * *$ & $-0.33 * * *$ & $-0.51 * * *$ \\
Year & 1998 & $-0.33 * * *$ & $-0.34 * * *$ & $-0.53 * * *$ \\
Year & 2002 & $-0.35 * * *$ & $-0.36 * * *$ & $-0.56 * * *$ \\
Year & 2006 & $-0.36 * * *$ & $-0.37 * * *$ & $-0.59 * * *$ \\
Year & 2010 & $-0.38 * * *$ & $-0.38 * * *$ & $-0.62 * * *$ \\
\hline
\end{tabular}

Notes: $*, * *$ and $* * *$ denote statistical significance at the $10 \%, 5 \%$ and $1 \%$ level, respectively. For both types of events marginal effects are computed at the mean value when affected (DI $1=0.493$ and DI2 $=0.207)$.

First, our results could be driven by trends in the composition of Type 1 and Type 2 events, with the former increasingly driven by cumulative heat over the growing season and the latter by rainfall deficiency. Figure 4(a) shows the ratio of normalised CDD to normalised rainfall deficiency. A higher value indicates a higher contribution of CDD relative to rainfall in our index. The plotted linear trend in Figure 4(a) suggests that the composition of the two types of drought has followed different patterns over time, with Type 1 droughts increasingly driven by CDD and Type 2 droughts increasingly driven by rainfall deficiency. As shown in Figure 4(b), this change in composition is not captured by the index value, which has followed very similar trends. However, should rainfall deficiency and CDD increases be associated with different impacts, the change in composition could partially explain the increase in impacts over time for Type 2 droughts.

Second, Type 2 droughts seem to be increasingly preceded by dry years, which could increase the impact of this type of drought, turning what we have defined in this study as a 
meteorological drought into a potential hydrological drought. Figure 4(c) plots the proportion of affected districts (by drought type) in a given year conditional on the previous year being drier than average (i.e. either a Type 1 or Type 2 drought). This figure shows contrasting trends for Type 1 and Type 2 events, with the proportion of the former declining slightly while the proportion of the latter follows an increasing trend. Figure 4(d), which plots the average intensity of droughts (by type) if preceded by a drier-than-average year, also suggests that the intensity of Type 2 droughts increased at a faster rate than that of Type 1 droughts. ${ }^{13}$

Figure 4: Ratio of temperature to rainfall and drought intensity following dry years

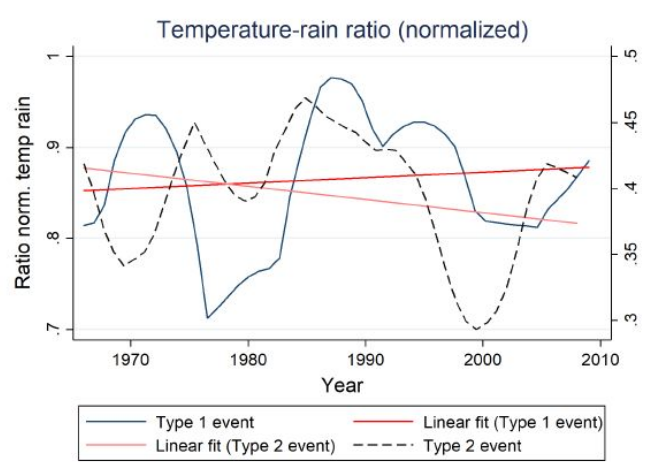

(a) Ratio of temperature to rainfall over time

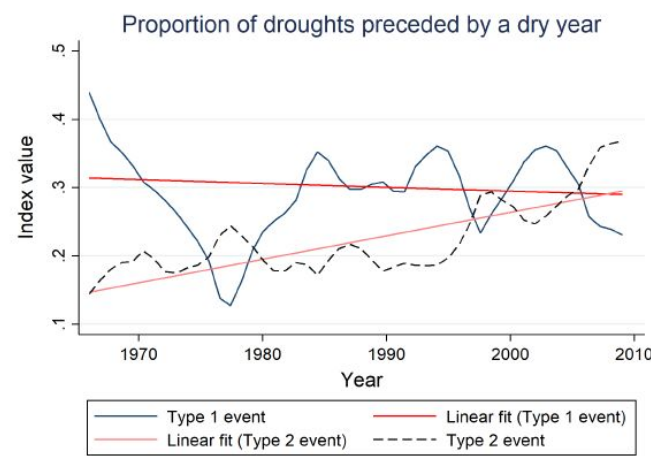

(c) Average proportion of dry events following a dry event, by type

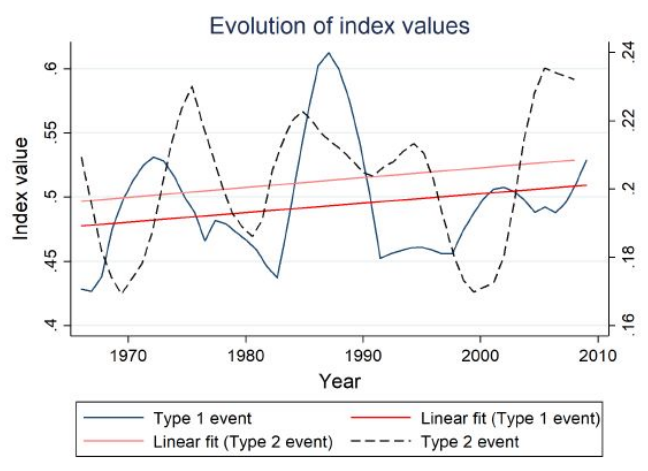

(b) Drought intensity over time, (affected only)

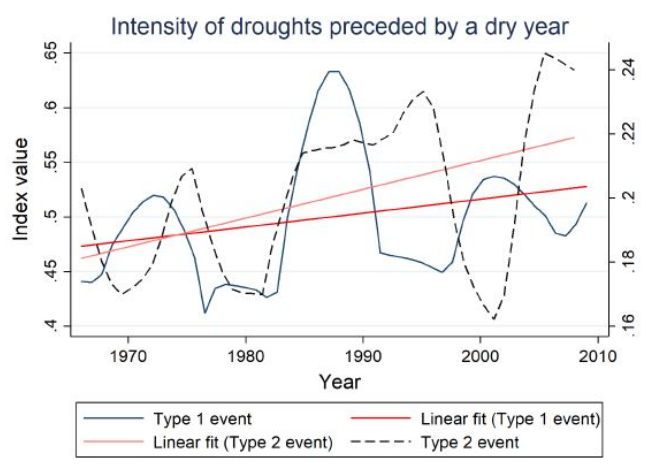

(d) Average index value following a dry year, by type (affected only)

Notes: All sub-figures use a bandwidth of 2 for the local polynomial. For sub-figures (a), (b) and (d) the left y-axis refers to values for type 1 events whereas the y-axis on the righ-hand side shows values for type 2 events. Sub-figure (a) plots the ratio of the normalized cooling-degree days over the normalized negative cumulative rainfall for all events where the index is positive. A lower value of this ratio implies that the contribution of temperature to the drought index is lower. Sub-figure (b) plots the changes of the index values over time for affected districts. Sub-figure (c) plots the proportion of drought affected districts if either index was positive the preceding year. Finally, Sub-figure (d) plots the index value if the preceding year was characterised by a positive index value.

\footnotetext{
${ }^{13} \mathrm{We}$ also test whether the differences in trends for panels (a)-(d) in Figure 4 are statistically different. They are statistically significant (at the 1\% levels) for panels (a) and (c), but not for panels (b) and (d).
} 
Supporting evidence that lagged dry events might be associated with larger drought impacts is given by Shah and Kishore (2009), who argue that in years of below-average precipitation more groundwater tends to be extracted to compensate for rainfall deficiency and minimize production losses. However, the extent to which losses can be minimised depends on the availability of groundwater. For example, 2002-2003 was an exceptionally dry period preceded by two moderately dry years, which put additional pressure on groundwater resources. These resources had not sufficiently recovered by 2002-2003 thus limiting their capacity to minimise production losses.

\section{Estimating Yield and Economic Losses}

We estimate yield impacts and economic costs by running simple simulations using our estimated regressions in Table 3 (see Appendix B). Column 1 shows the predicted impacts of Type 1 droughts when Type 2 droughts are excluded (i.e. using results from columns 1 and 3 in Table 3) and columns 2-4 show the impacts of both types of drought (i.e. using results from columns 2 and 4 in Table 3). Specifically, we estimate the: (i) average yield loss for an affected district over the sample period; (ii) average total production loss for an affected district over the sample period; (iii) average value of production loss for an affected district; (iv) average yearly production loss across all the Indian districts in our sample; and, (v) the average yearly cost of predicted production losses across sampled districts. A summary of estimates is presented in Table 6.

From Table 6, we note that, despite a higher estimated coefficient, total yield and economic losses from Type 2 droughts are smaller than those from Type 1 droughts. This is due to the index values for Type 2 droughts being substantially lower (approximately half) in affected districts. Depending on the specification used, we estimate the range of average yield 
loss per district at 130-155 kg/ha (Table 6, column 2) and 84-121 kg/ha (Table 6, column 3) for Type 1 and Type 2 droughts, respectively. These smaller impacts on yield translate into lower total economic costs. Whereas we estimate that, in a given year, the total economic cost of a Type 1 drought ranges, on average, between USD 224-265 million (Table 6, column 2), ${ }^{14}$ this falls to USD 121-185 million for a Type 2 drought (Table 6, column 3). We note that the estimated impact of Type 1 droughts increases when Type 2 droughts are included. This is due to the fact that, when Type 2 droughts are excluded, they are part of the 'no drought' counterfactual, which is likely to bias the Type 1 drought impacts downwards.

Omitting Type 2 droughts can lead to a lower estimate of Type 1 drought impacts. These effects are quantifiably large as we illustrate by comparing the first two columns of Table 6 for the full sample. Average yield losses are estimated to be approximately $25-27 \%$ higher (from $104-122 \mathrm{~kg} /$ ha to $130-155 \mathrm{~kg} / \mathrm{ha}$ ) when Type 2 droughts are included. These estimates have a substantial effect on the estimated average annual cost. This ranges from USD 179-204 million (Table 6, column 1) when Type 2 droughts are omitted compared to USD 224-265 million (Table 6, column 2) when they are included, which represents a 25-30\% increase. Thus, if estimating the economic cost of Type 1 droughts without accounting for Type 2 droughts, the average yearly total costs of drought would approximate USD 179-204 million. Including Type 2 droughts raises this total cost by $121-124 \%$ to USD $402-450$ million (Table 6 , column 4). Overall, both specifications suggest that Type 2 droughts are responsible for about $35-40 \%$ of the total ex-post economic value of yield losses.

\footnotetext{
${ }^{14}$ Crop prices in Indian rupees are converted into USD using the average monthly exchange rate obtained from http://www.X-rates.com/average/?from=USD\&to $=I N R \& a m o u n t=1 \&$ year $=2008$. More details on how prices are computed are available in the Appendix (B).
} 
Table 6: Cost estimates

\begin{tabular}{lllll}
\hline & \multicolumn{5}{c}{ Main } \\
\hline & \multicolumn{1}{c}{1} & \multicolumn{2}{c}{2} & \multicolumn{1}{c}{4} \\
\hline & Type 1 (only) & Type 1 (sep) & Type 2 (sep) & 2 types (sep) \\
\hline & \multicolumn{5}{c}{ Log-levels } \\
\hline Av. yield loss (district) (t/ha) & 0.122 & 0.155 & 0.121 & 0.139 \\
Av. production loss (district) (1,000t) & 14.328 & 18.594 & 15.379 & 17.122 \\
Av. production cost (district) (mil USD) & 4.291 & 5.568 & 4.606 & 5.128 \\
Av. yearly total production loss (1,000 t) & 682.218 & 885.338 & 618.652 & 1503.990 \\
Av. yearly total cost (mil USD) & 204.306 & 265.135 & 185.270 & 450.405 \\
\hline & \multicolumn{4}{c}{ Levels } \\
\hline Av. yield loss (district) (t/ha) & 0.104 & 0.130 & 0.084 & 0.109 \\
Av. production loss (district) (1,000t) & 12.601 & 15.839 & 10.128 & 13.221 \\
Av. production cost (district) (mil USD) & 3.774 & 4.743 & 3.033 & 3.959 \\
Av. yearly total production loss (1,000 t) & 597.707 & 749.146 & 405.792 & 1154.938 \\
Av. yearly total cost (mil USD) & 178.997 & 224.349 & 121.524 & 345.873 \\
\hline
\end{tabular}

Notes:Rice prices use the 2008 prices converted into USD using the average monthly exchange rate for 2008 . All numbers were rounded to two decimal places. The results presented in column 4 are simply the aggregation of the results presented in columns 2 and 3.

\subsection{Forecasting accuracy}

To test the forecasting accuracy of our index, an out-of-sample prediction on yield (levels) is undertaken using: 1) the DI1 and DI2 index (separately); 2) the normalized YuBabcock index $(D I 1) ; 3)$ the combined $D I 1$ and $D I 2$ index $(D I 12) ; 4)$ a rainfall-only index (proportion of rainfall against the long-term average for years below normal); and, 5) a CDD only index. We estimate out-of-sample accuracy by estimating the models up to 2000 and forecasting yield from 2001 to $2006 .^{15}$ The year 2000 was chosen as a cut-off period as the 2001-2006 period is notoriously difficult to predict; many districts were affected by drought so the results can be seen as a lower-bound in terms of forecasting accuracy. ${ }^{16}$ All the statistics used to evaluate the forecast accuracy are bootstrapped (100 repetitions), which gives an indication of the sensitivity of the results (see also Appendix C).

\footnotetext{
15 We performed the same exercise for different cut-off years and results do not change substantially.

16 Forecasting performance is better for years other than the cut-off period.
} 
The results are shown in Appendix Table 8 in which we also report four indicators of forecast accuracy, namely the Mean Absolute Error (MAE), the Root Mean Square Error (RMSE) and the proportion of false negatives (FN) and positives (FP). We define false positives as cases where the observed yield was not $10 \%$ below normal ${ }^{17}$ yield (drought), but our model predicted yields lower than $10 \%$ below normal. Conversely, false negatives are defined as cases where observed yields are lower than $10 \%$ below normal, but the model predicts yields above this level.

Overall, the separate indices (DI1 and DI2) and the combined index (DI12) perform better than other indices in all metrics (Appendix table 8). The FP and FN rates are approximately $16 \%$ and $24 \%$, respectively. Also, while the DI 12 model performs better than alternative indices, the difference in performance is not statistically different and the MAE remains large (above $500 \mathrm{~kg} / \mathrm{ha}$ ). This is mainly due to the fact that the estimated model was not primarily conceived for forecasting. In Appendix C, we show how forecasting performance can be improved with some very minor alterations in terms of the chosen specification; Appendix table 10 shows the results of these alternative specifications.

\section{Discussion}

Overall, three main findings emerge from our analysis. First, we show that two types of dry event, defined according to whether they have an above- or below-average value of CDD, have significant impacts on rice productivity in India. A consideration of the latter type - Type 2 - is shown to be critical, especially in a setting where there has been a clear increase in the number of such events in recent years. If an assessment of economic impacts is performed solely based on Type 1 droughts alone, i.e. those considered by Birthal et al. (2015),

\footnotetext{
${ }^{17}$ Normal yield is defined as the median yield for the five years preceding the cut-off.
} 
approximately half of all potential dry events would be overlooked. Our results strongly suggest that Type 2 events have had quite a severe impact on rice yields.

Second, the impacts are ameliorated differently when rice is irrigated. Specifically, absolute losses increase with the proportion of rice area under irrigation as a result of higher yields, although they decline as a proportion of total yield. We also find that irrigation seems to be more effective at reducing drought-induced yield losses from Type 2 droughts than Type 1 droughts. This suggests that the potential effects of irrigation in mitigating drought-induced impacts of climate change hinges on drought typology.

Third, there is some evidence that marginal impacts over time differ depending on drought type. Overall, absolute yield losses have either remained fairly constant or increased over time. As a proportion of yield, Type 1 drought losses have become smaller while Type 2 losses have risen. We attribute this partially to the fact that Type 2 droughts have become increasingly severe over time and have increasingly been preceded by dry years, which may have accentuated the impacts of this type of drought.

The economic value of production losses attributable to Type 2 droughts is calculated to be approximately $70 \%$ of the value of losses attributable to Type 1 droughts. Also, the omission of Type 2 droughts underestimates the economic value of production losses caused by to Type 1 droughts, by around $27 \%$. While we acknowledge that our back-of-the envelope estimates are based on a number of assumptions regarding prices and so forth, they do suggest that we have found sufficient empirical evidence and an economic rationale to justify the inclusion of Type 2 droughts, both in ex-post analyses of drought impact and in forecasts of impact.

We acknowledge that our index has a number of technical limitations. First, similar to any index based on relative values, our index may have limited transferability because index 
values change when the minimum and maximum values change over time. Thus, its values might not be easily comparable across different regions, e.g. dry vs humid areas. Second, the normalization process is bounded between 0 and 1 . If a given district has a very large outlier in a given year but records lower values in other years then this would indicate a low value in the drought index thus masking what might have been a severe drought year. The third potential weakness arises from the multiplicative nature of the index. Whenever temperature is close to 0 , this can lead to a very low value of the drought index despite very deficient rainfall, an issue that also applies to Yu and Babcock's index. Fourth, similar to their index, our index does not take into account intra-seasonal deficiencies in rainfall, which have been shown to have important impacts on agricultural productivity, ${ }^{18}$ e.g. Fishman (2016). Finally, similar to most drought indices, our index does not take into account (rare) multi-year droughts because this would require an index with 'memory' that takes into account soil moisture conditions. That said, since drought in India is mainly driven by variation in the annual monsoon, we argue that using an annual measure of monsoon rainfall is of greater relevance when estimating drought impact in our setting.

\subsection{Behavioural responses to drought}

Our empirical analysis precludes a consideration of the ex-ante and ex-post behavioural responses to drought (Oviedo and Moroz, 2014). Previous research has shown that farmers often engage in lower-risk-lower-return activities as coping strategies to cope with anticipated weather shocks, e.g. the adoption of less-profitable crop portfolios less sensitive to rainfall deviations (Rosensweig and Wolpin, 1993), field scattering (Goland, 1993) and the adoption of low-risk-low-return crops (Dercon, 2008). Such strategies have been shown to have large negative impacts on profits and capital stock growth. Similarly, ex-post responses to drought

\footnotetext{
${ }^{18}$ However, we show that when we include a monthly index for different months during the cropping season, our main results still hold (see Appendix Tables 6 and 7).
} 
have been shown to have negative impacts, e.g. a disinvestment in productive assets (Rosensweig and Wolpin, 1993), a slowdown in the post-drought asset recovery process (Jodha, 1978), as well as effects on human capital (Shah and Steinberg, 2017).

In our particular context, we might expect a reduction in rice areas in anticipation or as a result of a drought. Higher perceived drought risk may drive higher levels of diversification and hence, potential yield losses from rice specialization. Divesting in productive inputs (seeds, livestock) as a result of a previous drought is another type of behavioural response that is not captured in our data. The implication is that our cost estimates, which are only based on yield losses, are likely to represent an underestimate of the true economic cost of drought's impact on rice yield in India.

\subsection{Policy implications}

In 2016, the IMD officially stopped using the word 'drought', as part of a policy decision to move away from the use of terms it did not consider to have much scientific precision (Koshy and Vasudeva, 2016). An All India Drought Year was changed to a 'Deficient Year' while an All India Severe Drought Year became a 'Large Deficient Year'. Yet, these events are still defined according to rainfall shortfall and the proportion of area affected, as described in Section 3. The declaration of droughts remains the prerogative of India's States and while a rainfall shortfall combined with area affected allows a State to declare an 'agricultural' and 'meteorological' drought, this gives no indication of the impact on yield.

Our index covers all events defined as 'Deficient Years' by the IMD. Since it incorporates the impact of temperature as well as rainfall shortfalls on productivity, it could complement the existing efforts of Indian policy-makers. It could also be adopted in other settings given its simplicity, reproducibility, and flexibility, e.g. i.e. can be broken into 'bins' or adapted to other quadrants of interest. Since our index is based on readily-available, 
climactic data, it has the potential to be used as an input in the design of weather-based index insurance.

The results derived from application of our index have general implications for policy. We show that different water-stress heat-stress combinations have different impacts on yield. Thus, the future impacts of rising temperatures driven by climate change may not only depend on the frequency and intensity of drought but also the composition of drought, in terms of the relative importance of heat and water stress. This is of particular relevance in drought-prone areas.

Shaping the appropriate policy response to drought, particularly with respect to the costs of mitigation as well as climate adaptation in the agricultural sector, often involves the application of cost-benefit analysis, e.g. Mechler et al. (2008). In general, this and other economic modelling approaches, e.g. general equilibrium models, rely upon estimates of drought impacts on production (e.g. Pauw et al., 2011; WMO and GWP, 2017). Yet, if such models focus solely on events where the value of CDD is above average then this is likely to lead to a downward bias in the predicted economic benefits, by both reducing the potential gains from mitigation (since the gains from mitigation depend on the size of the impacts) and adaptation, hence lowering the cost of inaction.

\section{References}

Auffhammer M, Ramanathan V, and Vincent J (2012) Climate Change, the Monsoon, and Rice Yield in India. Climatic Change 111, 411-424.

Birthal P, Negi D, Khan M, and Agarwal S (2015) Is Indian Agriculture Becoming Resilient to Droughts? Evidence from Rice Production Systems. Food Policy 56, 1-12. 
Burgess R, Deschenes O, Donaldson D, and Greenstone M (2014) The Unequal Effects of Weather and Climate Change: Evidence from Mortality in India. Mimeo.

Chen S, Chen X and Xu J (2016) Impacts of climate change on agriculture: Evidence from China. Journal of Environmental Economics and Management 76, 105-124.

Deschênes O and Greenstone M (2007) The economic impacts of climate change: evidence from agricultural output and random fluctuations in weather. American Economic Review 97(1), 354-385.

Dercon (2008) Fate and Fear: Risk and Its Consequences in Africa. Journal of African Economies 17, ii97-ii127.

Diffenbaugh N, Swain D, and Touma D (2015) Anthropogenic Warming Has Increased Drought Risk in California. Proceedings of the National Academy of Sciences of the United States of America 112(13), 3931-3936.

Elbers C, Gunning JW and Kinsey B (2007) Growth and Risk: Methodology and Micro Evidence. World Bank Economic Review 21(1), 1-20.

Fishman R (2016) More uneven distributions overturn benefits of higher precipitation for crop yields. Environmental Research Letters 11(2), 024004.

Food and Agriculture Organization (2013) UN lays foundations for more drought resilient societies. Available at: http://www.fao.org/news/story/en/item/172030/icode/

Fontes F, Gorst A, and Palmer C (2017) Does Choice of Drought Index Influence Estimates of Drought-induced Cereal Losses in India? Centre for Climate Change Economics and Policy Working Paper No. 310 \& Grantham Research Institute on Climate Change and the Environment Working Paper No. 274, 2017.

Gadgil S and Gadgil S (2006) The Indian Monsoon, GDP and Agriculture. Economic and Political Weekly 41(47), 86-91. 
Gammans M, Mérel P, and Ortiz-Bobea A (2017) Negative impacts of climate change on cereal yields: statistical evidence from France. Environmental Research Letters 12(5), 054007.

GoI (2009) Manual for drought management. Technical report, Ministry of Agriculture, Department of Agriculture and Cooperation, Government of India, New Delhi.

Goland C (1993) Field Scattering as Agricultural Risk Management: A Case Study from Cuyo Cuyo, Department of Puno, Peru. Mountain Research and Development 13(4), 317-338.

Guiteras R (2009) The Impact of Climate Change on Indian Agriculture. Mimeo.

ICRISAT (2012) District Level Database Documentation. Technical report, ICRISAT-ICARIRRI Collaborative Research Project.

IPCC (2012) Managing the Risks of Extreme Events and Disasters to Advance Climate Change Adaptation. A Special Report of Working Groups I and II of the Intergovernmental Panel on Climate Change. Cambridge University Press, Cambridge, United Kingdom and New York, NY, USA.

Indian Meteorological Department, Government of India (undated) Frequently Asked Questions: FAQ. Available at: http://imd.gov.in/section/nhac/wxfaq.pdf

Jain SK and Kumar V (2012) Trend Analysis of Rainfall and Temperature Data for India. Current Science (Bangalore) 102(1), 37-49.

Jayachandran S (2006) Selling Labor Low: Wage Responses to Productivity Shocks in Developing Countries. Journal of Political Economy 114(3), 538-575.

Jodha NS (1978) Effectiveness of Farmers' Adjustment to Risk. Economic and Political Weekly 13(25), A38-41, A43-8.

Koshy J and Vasudeva V (2016) No More 'Droughts' in India, says IMD. The Hindu, January 12, 2016. Available at :http://www.thehindu.com/news/national/No-more\%E2\%80\%98droughts\%E2\%80\%99-in-India-says-IMD/article13994381.ece. 
Lamaoui M, Jemo M, Datla R and Bekkaoui F (2018) Heat and drought stresses in crops and approaches for their mitigation. Frontiers in chemistry $\mathbf{6}, 26$.

Lobell DB, Roberts MJ, Schlenker W, Braun N, Little BB, Rejesus RM and Hammer GL (2014) Greater sensitivity to drought accompanies maize yield increase in the US Midwest. Science 344(6183), 516-519.

Lobell D and Gourdji S (2012) The Influence of Climate Change on Global Crop Production. Plant Physiology 160(4), 1686-1697.

Lobell DB, Sibley A, and Ortiz-Monasterio JI (2012) Extreme heat effects on wheat senescence in India. Nature Climate Change 2(3), 186-189.

Luo Q (2011) Temperature thresholds and crop production: a review. Climatic Change, 109(34), 583-598.

Mechler R, Hochrainer S, Kull D, Chopde S, Singh P, and Wajih S (2008) Uttar Pradesh Drought Cost-Benefit Analysis, From Risk to Resilience. Working Paper No. 5., eds. Moench, M., Caspari, E. \& A. Pokhrel ISET, ISET-Nepal and ProVention, Kathmandu, Nepal.

Mishra A and Singh V (2010) A Review of Drought Concepts. Journal of Hydrology 391(12), 202-216.

Oviedo AM and Moroz H (2014) A Review of the Ex Post and Ex Ante Impacts of Risk. Background paper for the World Development Report 2014.

Pai DS, Sridhar L, Rajeevan M, Sreejith OP, Satbhai NS, and Mukhopadyay B (2014) Development of a New High Spatial Resolution $\left(0.25^{\circ}\right.$ x $\left.0.25^{\circ}\right)$ Long Period (1901-2010) Daily Gridded Rainfall Data Set over India and its Comparison with Existing Data Sets over the Region. Quarterly Journal of Meteorology, Hydrology and Geophysics 65(1), 433-436. 
Pai DS, Nair SA and Ramanathan AN (2013) Long term climatology and trends of heat waves over India during the recent 50 years (1961-2010). Mausam 64(4), 585-604.

Pandey S, Bhandari H, and Hardy B (2007) Economic Costs of Drought and Rice Farmers' Coping Mechanisms: A Cross-Country Comparative Analysis. International Rice Research Institute, Los Banos (Philippines).

Pauw K, Thurlow J, Bachu M, and Van Seventer DE (2011) The Economic Costs of Extreme Weather Events: A Hydrometeorological CGE Analysis for Malawi. Environment and Development Economics 16(2), 177-198.

Prasad PVV, Staggenborg SA, and Ristic (2008) Impacts of Drought and/or Heat Stress on Physiological, Developmental, Growth, and Yield Processes of Crop Plants. In Ahuja LH and Saseendran SA, (eds), Response of Crops to Limited Water: Understanding and modelling Water Stress Effects on Plant Growth Processes, Madison: ASA-CSSA, pp. 301-355.

Rosenzweig MR and Wolpin KI (1993) Credit Market Constraints, Consumption Smoothing, and the Accumulation of Durable Production Assets in Low-Income Countries: Investments in Bullocks in India. Journal of Political Economy 101(2), 223-244

Sarkar J (2011) Drought, its impacts and management: Scenario in India. In R. Shaw \& H. Nguyen (Eds.), Droughts in Asian Monsoon Region Bingley, UK: Emerald Group Publishing Limited, pp. 67-86.

Sarsons H (2015) Rainfall and Conflict: A Cautionary Tale. Journal of Development Economics, 115, 62-72.

Schlenker W and Lobell DB (2010). Robust negative impacts of climate change on African agriculture. Environmental Research Letters 5(1), 014010. 
Schlenker W and Roberts M (2009) Nonlinear Temperature Effects Indicate Severe Damages to U.S. Crop Yields under Climate Change. Proceedings of the National Academy of Sciences of the United States of America 106(37) 15594-15598.

Shah M and Steinberg B (2017) Drought of Opportunities: Contemporaneous and Long Term Impacts of Rainfall Shocks on Human Capital. Journal of Political Economy 125(2), 527-56.

Shah T and Kishore A (2009) Will the impact of the 2009 drought be different from 2002 ? Economic and Political Weekly 44(37), 11-14.

Sharma KD (2011) Rain-fed Agriculture Could Meet the Challenges of Food Security in India. Current Science 100(11), 1615-1616.

Srivastava AK, Rajeevan M, and Kshirsagar SR (2009) Development of a High Spatial Resolution Daily Gridded Temperature Data Set (1969-2005) for the Indian Region. Atmospheric Science Letters 10(4), 249-254.

Vicente-Serrano S, Lopez-Moreno L, Begueria S, Lorenzo-Lacruz J, Sanchez-Lorenzo A, Garcia-Ruiz J, Azorin-Molina C, Moran-Tejeda E, Revuelto J, Trigo R, Coelho F, and Espejo F (2014) Evidence of Increasing Drought Severity Caused by Temperature Rise in Southern Europe. Environmental Research Letters, 9, 044001.

\section{World Meteorological Organization (WMO) and Global Water Partnership (GWP)} (2017) Benefits of Action and Costs of Inaction: Drought Mitigation and Preparedness - A Literature Review (N. Gerber and A. Mirzabaev). Integrated Drought Management Programme (IDMP) Working Paper 1. WMO, Geneva, Switzerland and GWP, Stockholm, Sweden, 2017.

Wilhite DA (2000a) Drought as a natural hazard: concepts and definitions.

Wilhite DA (2000b) Drought: A Global Assessment. Routledge, London. 
Yu T, and Babcock B (2010) Are U.S. Corn and Soybeans Becoming More Drought Tolerant? American Journal of Agricultural Economics, 92(5), 1310-1323. 


\section{DOES CHOICE OF DROUGHT INDEX INFLUENCE ESTIMATES OF DROUGHT- INDUCED RICE LOSSES IN INDIA?}

\section{APPENDIX}

\section{(A) - Data and Variables}

The raw data file includes cumulative monthly rainfall data at the district level.

\section{Generating rainfall variables}

We start by generating the rainfall variable, which represents cumulative rainfall over the JuneSeptember period. A long-term average rainfall measure is then defined for each district. We take the average total cumulative rainfall over the growing season (June-September) for each district over the period 1956-2009.

For a given district, the general formula used is the following:

$$
T R_{i t}=\sum_{m=1}^{N} R_{m i t}
$$

Where the total rainfall in a given growing season for a given district $i$ in a given year $t$, is equal to the sum of the monthly cumulative rainfall over the June-September months ( $m$ to $M$ ) included in the growing season. To calculate the long-term average rainfall, we use the following formula:

$$
\operatorname{LTAR}_{i}=\frac{1}{54} \sum_{t=1956}^{T=2009} T R_{i t}
$$

Where the long-term average rainfall for a given district $i$ is simply calculated as the average total rainfall in that district over the 1956-2009 period. 


\section{Generating temperature variables}

We opt for a measure of cooling degree days $(C D D)$ to capture accumulated heat over the growing season (June-September, in our main specification). This captures the number of degree days above a reference (average) temperature, $D T A_{i}$, over a given time period. We use two alternative specifications for generating this variable.

Our first step is to define the average temperature over the growing season for each district between 1956 and 2009. For any given district, $C D D$ is estimated as:

$$
C D D_{i t}=\sum_{m=1}^{M} \sum_{d=1}^{D}\left(D T_{i m d}-D T A_{i}\right)
$$

Our long-term average $C D D$ is then calculated as follows:

$$
\operatorname{LTACDD}_{i}=\frac{1}{54} \sum_{t=1956}^{T=2009} C D D_{i t}
$$

where $d$ and $m$ represent a given day and month included in the growing season and $D$ and $M$ respectively represent the total numbers of days in a given month and the total number of months in the growing season; DT denotes the average daily temperature in district $i$ in day $d$ of month $m$; and, DTA represents the average growing season daily temperature for a given district over the 1956-2009 period. Next, we create $L T A C D D_{i}$, which is simply the average cumulative degree days above the mean daily temperature experienced by district $i$ over the 1956-2009 period.

\section{Generating drought indices}

Crucial to our analysis is the construction of a novel drought index. For our purposes, we develop three drought indices. Below we describe the steps we carry out for each one. 


\section{Yu-Babcock index}

We denote: total rainfall over the growing season $T R_{i t}$; the mean of total rainfall over the growing season over 1956-2009 $L T A R_{i}$; and, the standard deviation of $T R_{i t}$ as $S d T R_{i}$. We then obtain the standardized variable using the following formula:

$$
T R_{i t}^{\text {stand }}=\frac{T R_{i t}-L T A R_{i}}{s d T R_{i}}
$$

We proceed analogously for our $C D D_{i t}$ measure. Let: $C D D_{i t}$ be cumulative cooling degree days above the long-term mean temperature of a district during the growing season; $L T A C D D_{i}$ be long-term average cumulative cooling degree days in the growing season; and, $s d C D D_{i}$ be the standard deviation of $C D D_{i t}$. We compute the standardized variable:

$$
C D D_{i t}^{\text {stand }}=\frac{C D D_{i t}-L T A C D D_{i}}{s d C D D_{i}}
$$

Following this, we use the following to compute the Yu-Babcock index:

$$
D I_{i t}=\left[-\max \left(0, C D D_{i t}^{\text {stand }}\right)\right] *\left[\min \left(0, T R_{i t}^{\text {stand }}\right)\right]
$$

\section{Normalized indices}

We start by defining a variable that captures the deviations vis-à-vis the long term means of CDD and rainfall. Specifically, we calculate the deviations of CDD from the long-term averages by estimating:

$$
D C D D_{i t}=C D D_{i t}-L T A C D D_{i}
$$

Similarly, we calculate deviations of cumulative rainfall by estimating:

$$
D T R_{i t}=T R_{i t}-L T A R_{i}
$$

In contrast to the Yu-Babcock index, for the remaining indices we use a variable normalized between 0 and 1 , rather than a standardized value. We construct a variable, $M T R_{i t}$, which is 
simply the negative of $T R_{i t}$ (i.e. $M T R_{i t}=-T R_{i t}$ ). The following is estimated to obtain $N T R_{i t}$ and $N C D D_{i t}$ :

$$
\begin{gathered}
N T R_{i t}=\frac{M T R_{i t}-M T R_{i}^{\text {min }}}{M T R_{i}^{\text {max }}-M T R_{i}^{\text {min }}} \\
N C D D_{i t}=\frac{C D D_{i t}-C D D_{i}^{\text {min }}}{C D D_{i}^{\text {max }}-C D D_{i}^{\text {min }}}
\end{gathered}
$$

We differ from Yu and Babcock (2010) in creating a normalized version of the rainfall and CDD variables such that they vary strictly between 0 and 1 , with 1 indicating the most extreme value (the highest CDD and lowest rainfall) and 0 indicating the lowest value. From these two variables, we then create a normalized index $N R T I_{i t}$, which is simply a product of these variables:

$$
N R T I_{i t}=N T R_{i t} * N C D D_{i t}
$$

From this, we obtain two additional indices. First, our Type 1 drought index:

$$
D I 1_{i t}=\left\{\begin{array}{c}
N R T I_{\text {it }} \text { if } D T R_{i t}<0 \text { and } D C D D_{i t}>0 \\
0 \text { otherwise }
\end{array}\right.
$$

This is equivalent to a normalized version of the Yu-Babcock (2010) index. It only takes a nonzero value for events where rainfall deficiency and CDD are above average.

Second, we create our Type 2 drought index analogously using the following:

$$
D I 2_{i t}=\left\{\begin{array}{c}
N R T I_{i t} \text { if } D T R_{i t}<0 \text { and } D C D D_{i t}<0 \\
0 \text { otherwise }
\end{array}\right.
$$

This is the category omitted by $\mathrm{Yu}$ and Babcock. It only takes a non-zero value for events where rainfall deficiency is above-average and CDD is below average. 


\section{Determining the sample and generating trends}

After developing the drought indices, we create a data file which includes only the observations between 1966 and 2009, i.e. our sample period. This choice is purely driven by data availability. Prior to 1966, our dependent variables (production and yields) are missing from the ICRISAT dataset and hence, would have resulted in districts being dropped. Prior to starting our analysis, we also dropped any districts for which at least one observation is missing in order to keep a balanced panel. We then generate district-specific quadratic trends using the following:

$$
\begin{aligned}
& \text { trend }=t-1965 \\
& \text { trend_sq }=\text { trend }^{2}
\end{aligned}
$$

where $t$ denotes the year.

\section{(B) - Estimating Economic Impact}

As is made clear in the main text, the cost estimates generated in this paper are based purely on yield losses, without taking into account any potential changes in the cultivated area. Specifically, our cost estimates are derived using a series of seven steps. We detail all the assumptions and steps used throughout and discuss their relative strengths and weaknesses.

$\underline{\text { Step } 1 \text { - Obtain a national estimate of rice prices for each year: }}$

Crop prices: We generate a national weighted average of crop price by year (using the egen command and the user-written option wtmean), where the weight is determined by area of land under cultivation. As a result, we first generate, for each year, a weighted average of millet prices at the district-level.

We then use 2008 crop prices to estimate prices (and costs) in USD: Rice prices are estimated at 29.947 USD/quintal. These prices are obtained by obtaining the weighted average of rice prices in India for 2008 (in Rupees) and converting this using the averages of the 2008 monthly 
$\begin{array}{llll}\text { exchange } & \text { rates } & \text { http://www.X- }\end{array}$ $\underline{\text { rates. }}$ com/average/?from $=$ USD \& to $=I N R \&$ amount $=1 \&$ year $=2008$.

All of the tables are also constructed using nominal yearly prices in Rupees and are available from the authors upon request.

Weaknesses and strengths of the assumptions:

National rice prices. For any given year, there are large differences in prices across districts. It could be argued that prices at the district- or state-level may be more appropriate. However, there are issues with missing price data at the district-level and, to a lesser extent, at the statelevel even for cases where there is a non-zero quantity reported. This is the main reason why we opt for national prices.

Using fixed rice prices in USD: Using a fixed price throughout the sample period implies that the estimates of costs will vary depending on the chosen year since the choice of the year will, by definition drive both the exchange rate and the price level. Yet, output losses in the early periods are made comparable to losses in later periods since they are given the same value. Using nominal prices could lead to the economic cost of drought artificially increasing over time as nominal prices have trended upwards over the sample period. In any case, we have also performed this exercise using nominal prices in rupees and the results are available from the authors upon request.

Step 2 - Estimate the regression of interest:

We estimate a fixed-effects model per (3) in the main text.

Step 3 - Estimate the yield losses:

After Stata has generated the output for the regression in Step 2, we operationalise the following steps: 
- $\underline{\text { Step } 3.1}$ - Predict the yield for drought when $D I 1_{i t}>0$ or $D I 2_{i t}>0$ (i.e. when the given district is drought affected). We do this by using the levpredict command following the estimation of the regression before replacing observations not affected by drought with an empty observation. We denote this variable $y h a t_{d}$. Note, to limit potential biases in the estimates of overall costs, we remove districts with implausible predicted yields, which we define as yields below $100 \mathrm{~kg} / \mathrm{ha}$ and above 5 tonnes/ha). This assumption, however, affects very few observations (less than $0.01 \%$ of total events).

- $\underline{\text { Step } 3.2}$ - Predict the yield variable under no drought (i.e. when $D I 1_{i t}=0$ or $D I 2_{i t}=0$ ). We rename the original variables DI1original ${ }_{i t}$ and DI2original it $_{\text {, }}$ and create two new temporary variables: DI 1 temp $p_{i t}=0$ and $D I 2$ temp $_{i t}=0$. We then use the levpredict command to obtain predicted yield and a variable denoted $y$ hat ${ }_{n d}$. The

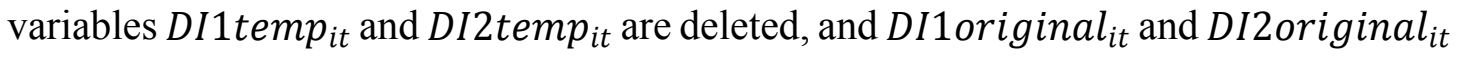
are, respectively, renamed $D I 1_{i t}$ and $D I 2_{i t}$. We replace $l y h a t_{n d}$ with an empty observation for every case where $D I 1$ temp $p_{i t}=0$ and DI2temp $p_{i t}=0$ (non-drought affected case).

- $\underline{\text { Step } 3.3}$ - Obtain predicted yield losses by simply subtracting the predicted yield under no drought (Step 3.2) by the actual predicted yield (Step 3.1) for all cases when $D I 1_{i t}$ $>0$ or $D I 2_{i t}>0$. Formally, we calculate ylosses $=y_{h a t_{n d}}-y_{h a t_{d}}$.

- Step 3.4 - Obtain predicted yield losses by drought type by simply subtracting the predicted yield under no drought by the actual predicted yield for each type of drought separately. Thus, we estimate: losses $_{1}=$ yhat $_{n d}-y$ hat $_{d}$ if $D I 1_{i t}>0$; and, ylosses 2 $=y h t_{n d}-y h a t_{d}$ if $D I 2_{i t}>0$. Note the two types of drought are mutually exclusive (i.e. it is impossible for a district to simultaneously have a Type 1 and a Type 2 drought). 
$\underline{\text { Step } 4 \text { - Estimate district-level production losses: }}$

This requires three further steps:

- $\quad$ Step 4.1 - Convert land area to ha. As highlighted in the supporting documentation, ${ }^{1}$ the land-use data is in 000 's of ha. As a result we simply multiply cereal area by 1,000 to derive the cereal area in ha.

- $\quad$ Step 4.2 - Convert yield losses to 1,000t/ha. Currently, our yield losses are in t/ha. We thus convert the yield losses to 1,000 t/ha by dividing ylosses by 1,000 .

- $\underline{\text { Step } 4.3}$ - Get the total district production losses (in 1,000t). Obtain the product of the variable obtained in Step 4.1 by that obtained in Step 4.2.

\section{$\underline{\text { Step } 5 \text { - Estimate the district-level cost of production losses: }}$}

To do this we perform two further steps:

- $\underline{\text { Step } 5.1}$ - Convert price data to million USD/1,000t. For the results shown in the paper, our price data are in USD per quintal (as explained in Step 3.1) and our production loss data (estimated in Step 4.3) are in 1,000t. To obtain the price data in million USD per $1,000 \mathrm{t}$ we divide our price level by 100 . Note, a quintal is $100 \mathrm{~kg}$. To convert it into $1,000 \mathrm{t}(1,000,000 \mathrm{~kg})$ we multiply the price data by 10,000 . However, since we want the data in million USD rather than USD, we divide this by $1,000,000$. Thus, price* $10,000 / 1,000,000=$ price $/ 100$

- $\underline{\text { Step } 5.2}$ - Obtain total value of production losses. After obtaining prices in million USD/1,000t we multiply the variable derived in Step 5.1 by the variable derived in Step 4.3 to obtain the total value of production losses in USD millions. Note, for our estimates in Rupees, we apply the exact same procedure using yearly nominal prices.

\footnotetext{
${ }^{1}$ See: http://vdsa.icrisat.ac.in/Include/document/all-apportioned-web-document.pdf
} 


\section{Step 6 - Estimate total yearly production losses:}

To obtain this measure in $1,000 \mathrm{t}$ we sum estimated total production losses of each affected district in a given year. We use the total function of the egen command. Note that the value in the table represents the unweighted average yearly loss.

\section{$\underline{\text { Step } 7 \text { - Estimate total yearly production costs: }}$}

To obtain this measure in millions of Rupees, we simply sum the estimated total value of the production losses of each affected district in a given year. We use the egen command with the total function. Note again that the value in the table represents the unweighted average yearly loss.

\section{(C) - Estimating Forecasting Accuracy}

For the results in Appendix table 8, we estimate the forecasting accuracy of five different models, namely:

- Model 1: DI1 + DI2 separate

- Model 2: DI1 (normalized Babcock index)

- Model 3: DI1 + DI2 in a unique index

- Model 4: Rainfall index (proportion of rainfall below normal)

- Model 5: CDD index - CDD above long-term average growing-season daily temperature for the district

We define 2000 as the main cut-off point to evaluate the forecasting accuracy of our model. In addition, we also test the sensitivity to the choice of cut-off point by using alternative cut-off points $(1990,1995$, and 2004). For each cut-off point, we carry out the following steps: 
1. For each model and evaluation period, we estimate the following model (in levels) up to the last year of the evaluation period (e.g. up to 2000), using a fixed effects regression:

$y_{i t}$

$$
\begin{aligned}
& =\alpha_{i}+\gamma_{t}+\delta_{i 1} * t+\delta_{i 2} * t^{2}+\beta_{1 q} D I_{i t q}+\beta_{2 q} D I_{i t q}^{2}+\beta_{3 q} D I_{i t q} * t+\beta_{4 q} D I_{i t q}^{2} * t+\beta_{5 q} \\
& D I_{i t q} * \text { propirri }_{i t}+\beta_{6 q} D I_{i t q}^{2} * \text { propirri }_{i t}+\epsilon_{i t}
\end{aligned}
$$

Note, for models 1-3 we use our drought indices. For model 4, DI becomes the rainfall index. For model 5, DI becomes the CDD index.

2. Once the relationship is estimated, we predict yields for the six years following the last year included in the regression (i.e. if 2000 is the last year, then we estimate predicted values for 2001-2006) using the coefficients from the model estimated up to the year 2000.

3. We then calculate the difference between the estimated values obtained in step 2 against the observed data

4. We then calculate the Mean Absolute Error (MAE) by computing the average absolute deviation between the predicted values and the observed values for the evaluation period.

5. We then calculate the Root Mean Squared Error (RMSE) by estimating the average squared-error and then taking the square root of this value.

6. For the False positives (FP) and false negatives (FN), we start by defining a 'normal' yield. We do this by calculating the district-specific median yield in the last 5 years included in the regression in step 1 (i.e. if 2000 is the last year included, a normal yield will be the median yield for the 1995-2000 period).

7. We then define a 'large' deviation from normal as a $10 \%$ negative deviation. 
8. We then generate a FP dummy variable which takes the value of 1 if our model predicts a yield below $90 \%$ of normal (i.e. a yield lower than a $10 \%$ negative deviation) and the observed value is above this threshold. The dummy takes a value of 0 otherwise.

9. We then generate a FN dummy variable which takes a value of 1 if our model predicts a yield above $90 \%$ of normal when the observed yield was lower than $90 \%$ belownormal. The dummy takes a value of 0 otherwise.

10. Finally, we run 100 bootstrap iterations and report the bootstrap standard errors for the RMSE, the MAE, the FN rate and the FP rate.

For the results in Appendix table 10, the procedure is identical to the one described for model 1 (which is the $D I 1+D I 2$ separate model, as before). For the other models, the procedure differs very slightly because the differences in yields are predicted. For the results in Appendix table 10, we estimate four alternative models, namely:

- Alt1: Dependent variable in first-differences and $D I 1+D I 2$ in a separate index. Specifically, we estimate the following model:

$\Delta y_{i t}$

$$
\begin{aligned}
& =\alpha_{i}+\beta_{1} D I 1_{i t}+\beta_{2} D I 1_{i t}^{2}+\beta_{3} D I 1_{i t} * \text { propirri }_{i t}+\beta_{4} D I 2_{i t}+\beta_{5} D I 2_{i t}^{2}+\beta_{6} D I 2_{i t} * \text { propirri }_{i t}+\beta_{7} \\
& Q I 3_{i t}+\beta_{8} Q I 4_{i t}+\beta_{9} \text { propirri }_{i t}+\beta_{10} \text { propirri }_{i t}^{2}+\epsilon_{i t}
\end{aligned}
$$

Where $\Delta y_{i t}$ is the first-difference in rice yields (levels) DII is the index for type 1 droughts, DI2 is the index value for type two droughts, propirri denotes the proportion of rice area under irrigation. $Q I 3$ and $Q I 4$ are the non-drought values analogous to $D I 1$ and DI2 (i.e. they represent the index values for years when rainfall was above average and temperature was below- (QI3) and above-average (QI4), respectively). Note, however, that the inclusion of $Q I 3$ and $Q I 4$ has only a marginal effect on the performance of the forecasting models. 
- Alt2: Dependent variable in first-differences and $D I 1+D I 2$ in a unique index. Specifically, we estimate the following model:

$\Delta y_{i t}$

$$
\begin{aligned}
& =\alpha_{i}+\beta_{1} D I 12_{i t}+\beta_{2} D I 12_{i t}^{2}+\beta_{3} D I 12_{i t} * \text { propirri }_{i t}+\beta_{4} Q I 3_{i t}+\beta_{5} Q I 4_{i t}+\beta_{6} \text { propirri }_{i t}+\beta_{7} \\
& \text { propirri }_{i t}^{2}+\epsilon_{i t}
\end{aligned}
$$

- Alt3: Dependent variable in first-differences and DII + DI2 in separate indices and disaggregated by month (choice of interactions was defined by experimenting with different specifications). The following model is estimated:

○ $\quad \Delta y_{i t}=\alpha_{i}+\beta_{1}$ DI1june $_{i t}+\beta_{2}$ DI1july $_{i t}+\beta_{3}$ DI1 july $_{i t} *$ propirri $_{i t}+\beta_{4}$ DI1august $_{i t}+$ $\beta_{5}$ DI1august $_{i t} *$ propirri $_{i t}+\beta_{6}$ DI1 september $_{i t}+\beta_{7}$ DI $_{\text {september }}^{2}+\beta_{8} D$

I1september $_{i t} *$ propirri $_{i t}+\beta_{9}$ DI2june $_{i t}+\beta_{10}$ DI2june $_{i t} *$ propirri $_{i t}+\beta_{11}$ DI2july $_{i t}$ $+\beta_{12}$ DI2july $_{i t} *$ propirri $_{i t}+\beta_{13}$ DI2 august $_{i t}+\beta_{14}$ DI2september $_{i t}+\beta_{15} D$ I2september $_{i t} *$ propirri $_{i t}+\beta_{16}$ DI $_{i t} *$ propirri $_{i t}+\beta_{17}$ QI3june $_{i t}+\beta_{18}$ QI3july $_{i t}+\beta_{19}$ QI3August $_{i t}+\beta_{20}$ QI3September $_{i t}+\beta_{21}$ QI june $_{i t}+\beta_{22}$ QI $_{24}$ july $+\beta_{23}$ QI4August + $\beta_{24}$ QI4september $+\beta_{25}$ propirri $_{i t}+\beta_{26}$ propirri $_{i t}^{2}+\epsilon_{i t}$

- Alt4: Dependent variable in first-differences and DII $+D I 2$ in a unique index and disaggregated by month (choice of interactions was defined by experimenting with different specifications). The estimated model is given by:

- $\quad \Delta y_{i t}=\alpha_{i}+\beta_{1}$ DI12june $_{i t}+\beta_{2}$ DI12june $_{i t} *$ propirri_it $+\beta_{3}$ DI12july $_{i t}+\beta_{4}$ DI12july $_{i t}$ $*$ propirri $_{i t}+\beta_{5}$ DI12august $_{i t}+\beta_{6}$ DI12august $_{i t} *$ propirri $_{i t}+\beta_{7}$ DI12september $_{i t}+$ $\beta_{8}$ DI12september $_{i t}^{2}+\beta_{9}$ DI12september $_{i t} *$ propirri $_{i t}+\beta_{9}$ propirri $_{i t}+\beta_{10}$ propirri $_{i t}^{2}$ $+\beta_{17}$ QI3june $_{i t}+\beta_{18}$ QI3july $_{i t}+\beta_{19}$ QI3August $_{i t}+\beta_{20}$ QI3September $_{i t}+\beta_{21}$ QI4jun $e_{i t}+\beta_{22}$ QI4july $+\beta_{23}$ QI4August $+\beta_{24}$ QI4september $+\epsilon_{i t}$

The main reason why these changes are likely to improve forecasting accuracy is that the original model was not originally intended for forecasting and addressing our research question required a large number of interactions, which may actually harm forecasting performance. Also, adding intra-annual drought index values is likely to be important as the month in which the drought occurs may have important yield implications.

For each of these models, we define 2000 as the main cut-off point to evaluate the forecasting accuracy of our model. In addition, we also test the sensitivity to the choice of cut-off point by 
using alternative cut-off points (1990, 1995, and 2004). For each cut-off point, we carry out the following steps:

1. For each model and evaluation period, we estimate the models described above (Alt1Alt4) up to the last year of the evaluation period (e.g. up to 1999 if 2000 is the evaluation period) using fixed effects.

2. Once the relationship is estimated, we predict yields for the six years following the last year included in the regression (i.e. if 1999 is the last year, then we estimate predicted values for 2000-2005) using the coefficients from the model estimated up to the year 1999. To predict yields, we first predict the difference in yields (which we now denote as $\left.d \hat{y_{i t}}\right)$. For the first period of the forecast, we then compute predicted yield as follows:

$$
\widehat{y_{i t}}=y_{i t-1}+d \hat{y_{i t}}
$$

For all other periods, we add the predicted $d \hat{y_{i t}}$ to the previous year predicted $\mathrm{y}\left(\hat{y_{i t}}\right)$. For example for year $\mathrm{t}+1$ :

$$
\widehat{y_{i t+1}}=\widehat{y_{i t}}+d \widehat{y_{i t+1}}=y_{i t-1}+d \widehat{y_{i t}}+d \widehat{y_{i t+1}}
$$

And so on for all periods.

3. Steps 3-10 are the same as the steps to obtain the estimates in Appendix table 8. Results are shown in Appendix table 11. 


\section{APPENDIX TABLES AND FIGURES}

Appendix table 1: Correlation coefficients and Spearman correlation coefficients

\begin{tabular}{|c|c|c|c|}
\hline \multicolumn{4}{|c|}{ Correlation coefficients } \\
\hline & Yu-Babcock & DI1 & DI2 \\
\hline Yu-Babcock & 1.000 & & \\
\hline DI1 & 0.787 & 1.000 & \\
\hline DI2 & -0.189 & -0.313 & 1.000 \\
\hline \multicolumn{4}{|c|}{ Spearman correlation coefficients } \\
\hline & Yu-Babcock & DI1 & DI2 \\
\hline Yu-Babcock & 1.000 & & \\
\hline DI1 & 0.994 & 1.000 & \\
\hline DI2 & -0.363 & -0.363 & 1.000 \\
\hline
\end{tabular}

Appendix table 2: R-squared

\begin{tabular}{lllllll}
\hline & \multicolumn{3}{c}{ Levels } & \multicolumn{3}{c}{ Log-levels } \\
\hline & FE only & FE + trends & All & FE only & FE + trends & All \\
\hline R-squared (within) & 0.501 & 0.731 & 0.744 & 0.464 & 0.597 & 0.632 \\
R-squared (between) & 0 & 0.604 & 0.792 & 0 & 0.064 & 0.344 \\
R-squared (overall) & 0.168 & 0.645 & 0.775 & 0.164 & 0.22 & 0.446 \\
\hline
\end{tabular}

Appendix table 3: F-tests

\begin{tabular}{lll}
\hline & Levels & Logs \\
\hline \multicolumn{3}{c}{ DI1=DI2 } \\
\hline F-statistic & 0.938 & 2.269 \\
p-value & 0.334 & 0.134 \\
\hline \multicolumn{2}{c}{ DI1 trends = DI2 trends } \\
\hline F-statistic & 0.846 & 5.918 \\
p-value & 0.359 & 0.016 \\
\hline All DI1 coeffs = All DI2 coeff \\
\hline F-statistic & 0.102 & 3.459 \\
p-value & 0.750 & 0.065 \\
\hline
\end{tabular}


Appendix table 4: Marginal elasticities (irrigation) proportion of area irrigated

\begin{tabular}{llccc}
\hline & \multicolumn{5}{c}{ Type 1 only } & Types 1 and 2 (sep.) \\
\hline Variable & Value & Type 1 & Type 1 & Type 2 \\
\hline \multicolumn{5}{c}{ Log-levels } \\
\hline Irrigated area (\%) & 0 & $-0.48 * * *$ & $-0.51 * * *$ & $-0.73 * * *$ \\
Irrigated area (\%) & 20 & $-0.41 * * *$ & $-0.43 * * *$ & $-0.60 * * *$ \\
Irrigated area (\%) & 40 & $-0.34 * * *$ & $-0.36 * * *$ & $-0.48 * * *$ \\
Irrigated area (\%) & 60 & $-0.27 * * *$ & $-0.28 * * *$ & $-0.35 * * *$ \\
Irrigated area (\%) & 80 & $-0.20 * * *$ & $-0.21 * * *$ & $-0.23 * * *$ \\
Irrigated area (\%) & 100 & $-0.13 * * *$ & $-0.13 * * *$ & -0.10 \\
\hline
\end{tabular}

Notes: *,** and $* * *$ denote statistical significance at the $10 \%, 5 \%$ and $1 \%$ level, respectively. For both types of events marginal effects are computed at the mean value when affected (DI1 $=0.493$ and $\mathrm{DI} 2=0.207$ ).

\section{Appendix table 5: Marginal elasticities (time)}

Type 1 only Types 1 and 2 (sep.)

Variable Value Type $1 \quad$ Type $1 \quad$ Type 2

Log-levels

\begin{tabular}{lllll}
\hline Year & 1966 & $-0.36 * * *$ & $-0.38 * * *$ & -0.06 \\
Year & 1970 & $-0.35 * * *$ & $-0.36 * * *$ & -0.12 \\
Year & 1974 & $-0.33 * * *$ & $-0.35 * * *$ & -0.17 \\
Year & 1978 & $-0.32 * * *$ & $-0.33 * * *$ & $-0.23 * *$ \\
Year & 1982 & $-0.30 * * *$ & $-0.32 * * *$ & $-0.29 * * *$ \\
Year & 1986 & $-0.29 * * *$ & $-0.30 * * *$ & $-0.35 * * *$ \\
Year & 1990 & $-0.27 * * *$ & $-0.28 * * *$ & $-0.41 * * *$ \\
Year & 1994 & $-0.26 * * *$ & $-0.27 * * *$ & $-0.47 * * *$ \\
Year & 1998 & $-0.24 * * *$ & $-0.25 * * *$ & $-0.53 * * *$ \\
Year & 2002 & $-0.23 * * *$ & $-0.24 * * *$ & $-0.59 * * *$ \\
Year & 2006 & $-0.21 * * *$ & $-0.22 * * *$ & $-0.65 * * *$ \\
Year & 2010 & $-0.20 * * *$ & $-0.21 * * *$ & $-0.71 * * *$ \\
\hline
\end{tabular}

Notes: $*, * *$ and $* * *$ denote statistical significance at the $10 \%, 5 \%$ and $1 \%$ level, respectively. For both types of events marginal effects are computed at the mean value when affected (DI $1=0.493$ and DI2=0.207). 
Appendix table 6: Full sample results index by month

\begin{tabular}{|c|c|c|c|c|}
\hline \multirow[b]{2}{*}{ Variables } & \multicolumn{2}{|c|}{ Levels } & \multicolumn{2}{|c|}{ Log-levels } \\
\hline & 1 & 2 & 3 & 4 \\
\hline & Linear & Squares & Linear & Squares \\
\hline DI1 June & $\begin{array}{l}-0.077 \text { **** } \\
(0.018)\end{array}$ & $\begin{array}{l}-0.103^{* *} \\
(0.051)\end{array}$ & $\begin{array}{l}-0.070^{* * * *} \\
(0.019)\end{array}$ & $\begin{array}{l}-0.169 * * * \\
(0.048)\end{array}$ \\
\hline DI1 ${ }^{2}$ June & & $\begin{array}{l}0.038 \\
(0.074)\end{array}$ & & $\begin{array}{l}0.142 * * \\
(0.064)\end{array}$ \\
\hline DI1 July & $\begin{array}{l}-0.057 * * \\
(0.029)\end{array}$ & $\begin{array}{l}-0.124 * * \\
(0.058)\end{array}$ & $\begin{array}{l}-0.084^{* * * *} \\
(0.025)\end{array}$ & $\begin{array}{l}-0.207 * * * \\
(0.063)\end{array}$ \\
\hline DI1 ${ }^{2}$ July & & $\begin{array}{l}0.105 \\
(0.083)\end{array}$ & & $\begin{array}{l}0.192 * * \\
(0.087)\end{array}$ \\
\hline DI1 August & $\begin{array}{l}-0.183^{* * *} * \\
(0.019)\end{array}$ & $\begin{array}{l}-0.233^{* * *} * \\
(0.056)\end{array}$ & $\begin{array}{l}-0.095^{* * *} \\
(0.017)\end{array}$ & $\begin{array}{l}-0.209 * * * \\
(0.048)\end{array}$ \\
\hline DI1 ${ }^{2}$ August & & $\begin{array}{l}0.075 \\
(0.082)\end{array}$ & & $\begin{array}{l}0.175 * * \\
(0.078)\end{array}$ \\
\hline DI1 September & $\begin{array}{l}-0.215^{* * *} * \\
(0.020)\end{array}$ & $\begin{array}{l}-0.134 * * \\
(0.052)\end{array}$ & $\begin{array}{l}-0.304 * * * \\
(0.026)\end{array}$ & $\begin{array}{l}-0.07 \\
(0.057)\end{array}$ \\
\hline DI1 ${ }^{2}$ September & & $\begin{array}{l}-0.119^{*} \\
(0.069)\end{array}$ & & $\begin{array}{l}-0.343 * * * \\
(0.089)\end{array}$ \\
\hline DI2 June & $\begin{array}{l}-0.209^{* * *} \\
(0.039)\end{array}$ & $\begin{array}{l}-0.341^{* *} \\
(0.132)\end{array}$ & $\begin{array}{l}-0.228^{* * *} \\
(0.052)\end{array}$ & $\begin{array}{l}-0.378^{* *} \\
(0.172)\end{array}$ \\
\hline DI2 ${ }^{2}$ June & & $\begin{array}{l}0.5 \\
(0.446)\end{array}$ & & $\begin{array}{l}0.54 \\
(0.691)\end{array}$ \\
\hline DI2 July & $\begin{array}{l}-0.132 * \\
(0.067)\end{array}$ & $\begin{array}{l}-0.392 * * \\
(0.183)\end{array}$ & $\begin{array}{l}-0.160^{* *} \\
(0.064)\end{array}$ & $\begin{array}{l}-0.423 * * * \\
(0.160)\end{array}$ \\
\hline DI2 ${ }^{2}$ July & & $\begin{array}{l}1.206 \\
(0.862)\end{array}$ & & $\begin{array}{l}1.067 \\
(0.706)\end{array}$ \\
\hline DI2 August & $\begin{array}{l}-0.345^{* * *} \\
(0.063)\end{array}$ & $\begin{array}{l}-0.452^{* * *} \\
(0.178)\end{array}$ & $\begin{array}{l}-0.234 * * * \\
(0.051)\end{array}$ & $\begin{array}{l}-0.561 * * * \\
(0.153)\end{array}$ \\
\hline DI2 ${ }^{2}$ August & & $\begin{array}{l}0.459 \\
(0.788)\end{array}$ & & $\begin{array}{l}1.454 * * \\
(0.657)\end{array}$ \\
\hline DI2 September & $\begin{array}{l}-0.104 * \\
(0.061)\end{array}$ & $\begin{array}{l}-0.320^{* * * *} \\
(0.122)\end{array}$ & $\begin{array}{l}-0.223^{* * *} \\
(0.061)\end{array}$ & $\begin{array}{l}-0.439 * * * \\
(0.101)\end{array}$ \\
\hline DI2 ${ }^{2}$ September & & $\begin{array}{l}1.025^{*} \\
(0.533)\end{array}$ & & $\begin{array}{l}1.179 * * * \\
(0.420)\end{array}$ \\
\hline Irrig & $\begin{array}{l}0.741 * * * \\
(0.153)\end{array}$ & $\begin{array}{l}0.742 * * * \\
(0.155)\end{array}$ & $\begin{array}{l}0.477 * * * \\
(0.130)\end{array}$ & $\begin{array}{l}0.476 * * * \\
(0.132)\end{array}$ \\
\hline Irrig $^{2}$ & $\begin{array}{l}-0.255^{* * * *} \\
(0.095)\end{array}$ & $\begin{array}{l}-0.255^{* * * *} \\
(0.096)\end{array}$ & $\begin{array}{l}-0.152 * \\
(0.078)\end{array}$ & $\begin{array}{l}-0.150 * \\
(0.079)\end{array}$ \\
\hline Constant & $\begin{array}{l}0.831 * * * \\
(0.060)\end{array}$ & $\begin{array}{l}0.833 * * * \\
(0.060)\end{array}$ & $\begin{array}{l}-0.295 * * * \\
(0.046)\end{array}$ & $\begin{array}{l}-0.282 * * * \\
(0.047)\end{array}$ \\
\hline Time trends & $\checkmark$ & $\checkmark$ & $\checkmark$ & $\checkmark$ \\
\hline District fixed effects & $\checkmark$ & $\checkmark$ & $\checkmark$ & $\checkmark$ \\
\hline Year fixed effects & $\checkmark$ & $\checkmark$ & $\checkmark$ & $\checkmark$ \\
\hline $\mathrm{N}$ & 6996 & 6996 & 6996 & 6996 \\
\hline Number of districts & 159 & 159 & 159 & 159 \\
\hline R-squared a & 0.733 & 0.733 & 0.608 & 0.611 \\
\hline R-squared w & 0.747 & 0.748 & 0.629 & 0.632 \\
\hline
\end{tabular}

Notes: Values in parentheses denote clustered standard errors at the district level. $*, * *$ and $* * *$ denote statistical significapge at the $10 \%, 5 \%$ and $1 \%$ level, respectively. Time trends denote quadratic district-specific trends. 
Appendix table 7: F-tests (index by month)

\begin{tabular}{ccccc}
\hline & \multicolumn{2}{c}{ Levels } & \multicolumn{2}{c}{ Log-levels } \\
\hline \multicolumn{1}{c}{1} & 2 & 3 & 4 \\
\hline Linear & Squares & Linear & Squares \\
\hline \multicolumn{3}{c}{ F-test type 2 jointly diff from 0} \\
\hline F-value & 37.930 & 2.248 & 5.912 & 5.279 \\
P-value & 0.000 & 0.136 & 0.016 & 0.023 \\
\hline \multicolumn{3}{r}{ F-test type 2 jointly diff from type 1 } \\
\hline F-value & 36.842 & 3.777 & 7.031 & 7.690 \\
P-value & 0.000 & 0.054 & 0.009 & 0.006 \\
\hline
\end{tabular}

Appendix table 8: Out of sample forecasts results (rice yield)

Model Estimated until 2000. Forecasted period: 2001-2006

\begin{tabular}{llllll}
\hline & DI12 (sep.) & DI1 only & DI12 (tog.) & Prop rainfall & CDD index \\
RMSE & 0.68 & 0.68 & $\mathbf{0 . 6 8}$ & 0.69 & 0.69 \\
BSE & 0.03 & 0.03 & 0.03 & 0.03 & 0.03 \\
MAE & 0.54 & 0.54 & $\mathbf{0 . 5 4}$ & 0.55 & 0.55 \\
BSE & 0.02 & 0.02 & 0.02 & 0.02 & 0.03 \\
FP & $16.7 \%$ & $16.6 \%$ & $\mathbf{1 6 . 2 \%}$ & $16.8 \%$ & $17.8 \%$ \\
FN & $23.9 \%$ & $24.0 \%$ & $\mathbf{2 3 . 7 \%}$ & $24.1 \%$ & $24.8 \%$ \\
FN + FP & $40.6 \%$ & $40.6 \%$ & $\mathbf{3 9 . 9 \%}$ & $40.9 \%$ & $42.7 \%$ \\
\hline \hline
\end{tabular}

Notes:RMSE stands for Root Mean Squared Error. MAE denotes the Mean Absolute Error. BSE denotes the Bootstrap Standard Errors (100 repetitions). FN is the rate of false negatives. FP is the rate of false positives and FN + FP is the sum of the false positives and false negatives. Numbers in bold denote the models that perform best for a given metric (i.e. lowest RMSE, MAE, FP, FN and FN+FP). 
Appendix table 9: Forecasting - Models (for years below the cut-off period)

\begin{tabular}{|c|c|c|c|c|c|c|c|c|}
\hline Variables & DI12 (sep.) & DI1 only & Variables & DI12 (tog.) & Variables & Prop. Rainfall & Variables & CDD index \\
\hline DI1 & $\begin{array}{l}-0.758^{* * *} \\
(0.128)\end{array}$ & $\begin{array}{l}-0.599 * * * \\
(0.124)\end{array}$ & DI12 & $\begin{array}{l}-0.823 * * * \\
(0.114)\end{array}$ & Rainfall & $\begin{array}{l}-1.672 * * * \\
(0.140)\end{array}$ & Temperature & $\begin{array}{l}-0.004 * * * \\
(0.001)\end{array}$ \\
\hline $\mathrm{DI} 1^{2}$ & $\begin{array}{l}0.451^{* *} \\
(0.180)\end{array}$ & $\begin{array}{l}0.318^{*} \\
(0.178)\end{array}$ & DI1 $2^{2}$ & $\begin{array}{l}0.543^{* * *} \\
(0.158)\end{array}$ & Rainfall $^{2}$ & $\begin{array}{l}1.703^{* * * *} \\
(0.152)\end{array}$ & Temperature $^{2}$ & $\begin{array}{l}0.000^{* * *} \\
(0.000)\end{array}$ \\
\hline DI1*time & $\begin{array}{l}0.015^{* * *} * \\
(0.005)\end{array}$ & $\begin{array}{l}0.013^{* *} \\
(0.005)\end{array}$ & DI12*time & $\begin{array}{l}0.017 * * * \\
(0.005)\end{array}$ & Rainfall*time & $\begin{array}{l}0.022 * * * \\
(0.006)\end{array}$ & Temperature*time & $\begin{array}{l}0.000 * * * \\
(0.000)\end{array}$ \\
\hline DI $1^{2 *}$ time & $\begin{array}{l}-0.016^{* *} \\
(0.008)\end{array}$ & $\begin{array}{l}-0.015^{*} \\
(0.008)\end{array}$ & DI1 $2^{2 *}$ time & $\begin{array}{l}-0.018^{* *} \\
(0.007)\end{array}$ & Rainfall $^{2 *}$ time & $\begin{array}{l}-0.024 * * * \\
(0.006)\end{array}$ & Temperature ${ }^{2 *}$ time & $\begin{array}{l}-0.000^{* * * *} \\
(0.000)\end{array}$ \\
\hline DI1*Irrig & $\begin{array}{l}0.204 \\
(0.134)\end{array}$ & $\begin{array}{l}0.177 \\
(0.133)\end{array}$ & DI12*Irrig & $\begin{array}{l}0.169 \\
(0.117)\end{array}$ & Rainfall*Irrig & $\begin{array}{l}0.521 * * * \\
(0.169)\end{array}$ & Temperature*Irrig & $\begin{array}{l}-0.001 \\
(0.001)\end{array}$ \\
\hline DI1 ${ }^{2 *}$ Irrig & $\begin{array}{l}-0.138 \\
(0.180)\end{array}$ & $\begin{array}{l}-0.101 \\
(0.181)\end{array}$ & DI1 $2^{2} *$ Irrig & $\begin{array}{l}-0.112 \\
(0.152)\end{array}$ & Rainfall ${ }^{2 *}$ Irrig & $\begin{array}{l}-0.513 * * * \\
(0.184)\end{array}$ & Temperature ${ }^{2 *}$ Irrig & $\begin{array}{l}0 \\
(0.000)\end{array}$ \\
\hline DI2 & $\begin{array}{l}-0.777^{* *} \\
(0.393)\end{array}$ & & & & & & & \\
\hline DI $2^{2}$ & $\begin{array}{l}0.006 \\
(1.404)\end{array}$ & & & & & & & \\
\hline DI2*time & $\begin{array}{l}-0.008 \\
(0.017)\end{array}$ & & & & & & & \\
\hline DI $2{ }^{2} *$ time & $\begin{array}{l}0.092 \\
(0.062)\end{array}$ & & & & & & & \\
\hline DI2*Irrig & $\begin{array}{l}1.010^{* * *} \\
(0.431)\end{array}$ & & & & & & & \\
\hline DI $2^{2 *}$ Irrig & $\begin{array}{l}-3.704^{* *} \\
(1.551)\end{array}$ & & & & & & & \\
\hline Irrig & $\begin{array}{l}0.561 * * * \\
(0.161)\end{array}$ & $\begin{array}{l}0.489 * * * \\
(0.167)\end{array}$ & Irrig & $\begin{array}{l}0.557 * * * \\
(0.163)\end{array}$ & Irrig & $\begin{array}{l}0.488 * * * \\
(0.159)\end{array}$ & Irrig & $\begin{array}{l}0.472 * * \\
(0.183)\end{array}$ \\
\hline Irrig $^{2}$ & $\begin{array}{l}-0.217^{*} \\
(0.114)\end{array}$ & $\begin{array}{l}-0.184 \\
(0.117)\end{array}$ & Irrig $^{2}$ & $\begin{array}{l}-0.210^{*} \\
(0.116)\end{array}$ & Irrig $^{2}$ & $\begin{array}{l}-0.201^{*} \\
(0.114)\end{array}$ & Irrig $^{2}$ & $\begin{array}{l}-0.157 \\
(0.116)\end{array}$ \\
\hline Constant & $\begin{array}{l}0.815^{* * * *} \\
(0.040)\end{array}$ & $\begin{array}{l}0.796^{* * * *} \\
(0.042)\end{array}$ & Constant & $\begin{array}{l}0.816^{* * * *} \\
(0.040)\end{array}$ & Constant & $\begin{array}{l}0.838^{* * * *} \\
(0.038)\end{array}$ & Constant & $\begin{array}{l}1.015^{* * *} \\
(0.058)\end{array}$ \\
\hline Time trends & $\checkmark$ & $\checkmark$ & & $\checkmark$ & & $\checkmark$ & & $\checkmark$ \\
\hline $\begin{array}{l}\text { District fixed effects } \\
\text { Year fixed effects }\end{array}$ & $\checkmark$ & $\checkmark$ & & $\checkmark$ & & $\checkmark$ & & $\checkmark$ \\
\hline $\mathrm{N}$ & 5565 & 5565 & & 5565 & & 5565 & & 5565 \\
\hline Number of districts & 159 & 159 & & 159 & & 159 & & 159 \\
\hline R-squared a & 0.712 & 0.705 & & 0.711 & & 0.717 & & 0.697 \\
\hline R-squared w & 0.729 & 0.722 & & 0.728 & & 0.734 & & 0.715 \\
\hline R-squared b & 0.744 & 0.736 & & 0.742 & & 0.727 & & 0.779 \\
\hline R-squared o & 0.739 & 0.731 & & 0.737 & & 0.729 & & 0.757 \\
\hline
\end{tabular}


Appendix table 10: Performance of out of sample forecasts results (alternative models, average)

Average performance over 4 cut-offs periods $(1990,1995,2000,2005)$

DI12 (sep.) Alt1 Alt2 Alt3 Alt4

$\begin{array}{llllll}\text { RMSE } & 0.665 & 0.462 & 0.461 & 0.466 & \mathbf{0 . 4 6 0} \\ \text { MAE } & 0.531 & 0.348 & 0.346 & 0.347 & \mathbf{0 . 3 4 3} \\ \text { FP } & 0.188 & 0.091 & 0.091 & \mathbf{0 . 0 8 6} & 0.089 \\ \text { FN } & 0.169 & 0.161 & 0.160 & \mathbf{0 . 1 5 3} & 0.156 \\ \text { FN+FP } & 0.357 & 0.251 & 0.252 & \mathbf{0 . 2 4 0} & 0.245\end{array}$

Notes:RMSE stands for Root Mean Squared Error. MAE denotes the Mean Absolute Error. BSE denotes the Bootstrap Standard Errors (100 repetitions). FN is the rate of false negatives. FP is the rate of false positives and $\mathrm{FN}+\mathrm{FP}$ is the sum of the false positives and false negatives. Numbers in bold denote the models that perform best for a given metric (i.e. lowest RMSE, MAE, FP, FN and $\mathrm{FN}+\mathrm{FP}$ ). The reported forecasting accuracy indicators are the average of the metrics estimated for four different cut-off points (1990, 1995, 2000, 2004). For each of these cut-off points the models were estimated until $t-1$ and then yields were forecasted for $t$ until $t+5$. See explanation in Appendix C. 
Appendix figure 1: Districts used in the sample

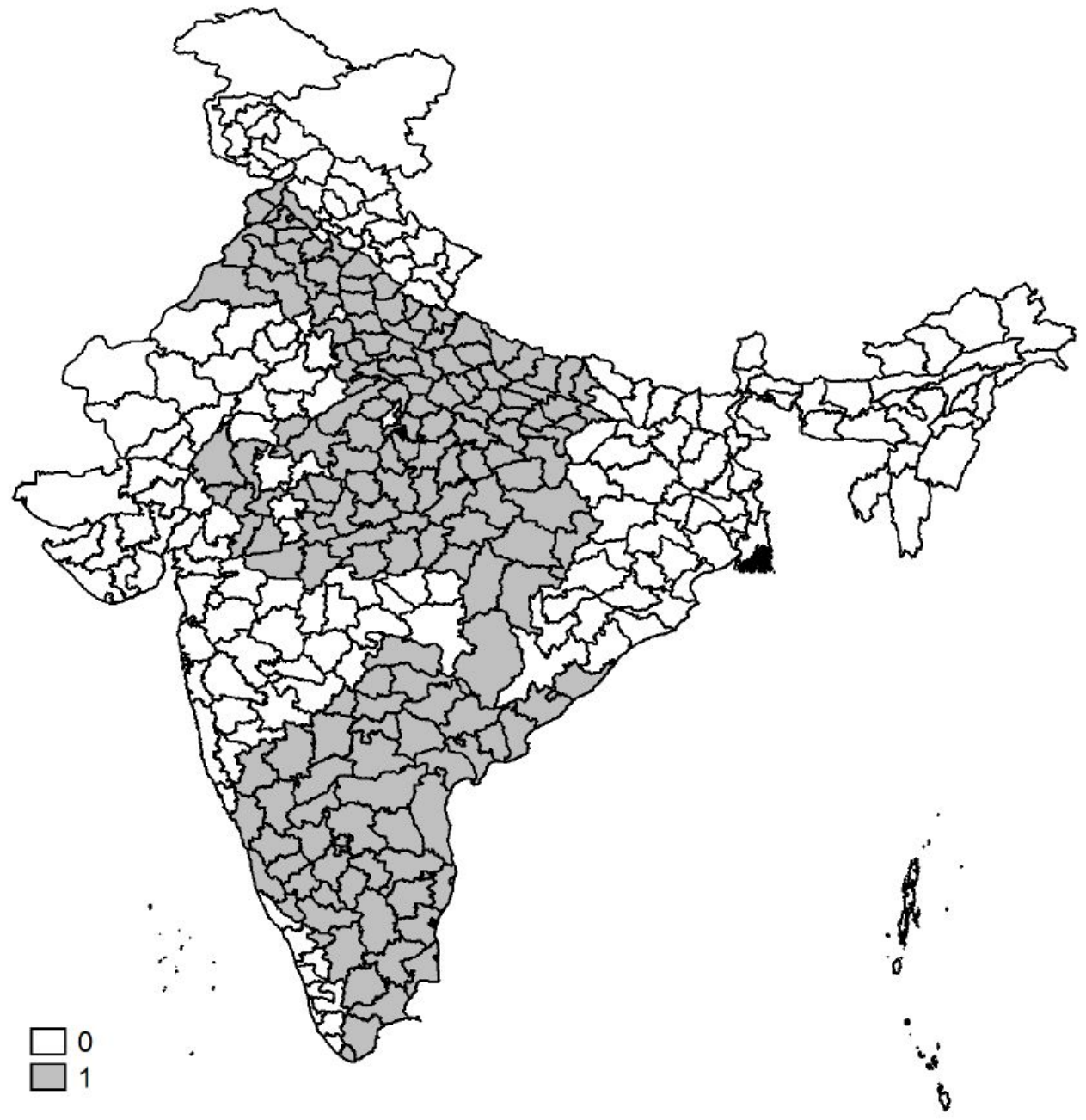

Notes: Districts in grey are those included in the final sample used for the estimations. 